\title{
Dynamic Supramolecular Polymers Built From Cucurbit[n]urils And Viologens
}

Henrique Dias Correia ${ }^{€,}$, Shagor Chowdhury ${ }^{\S}$, Ana Paula Ramos, Laure Guy ${ }^{\S}$, Grégoire JeanFrançois Demets ${ }^{* *}$, Christophe Bucher ${ }^{\S *}$

§Univ Lyon, Ens de Lyon, CNRS UMR 5182, Université Claude Bernard Lyon 1, Laboratoire de Chimie, F69342, Lyon, France.Christophe.bucher@ens-Iyon.fr

${ }^{€}$ Escola Técnica ETEC Ângelo Cavalheiro, Rua José Correia Filho 750 CEP 140150-000 Serrana SP Brazil

${ }^{¥} D Q-F F C L R P$, Universidade de São Paulo. Av. Bandeirantes 3900, CEP 14040-901, RibeirãoPreto S.P. Brazil. (55) 1633154860 greg@usp.br

\begin{abstract}
This review article focuses on supramolecular assemblies involving cucurbit[n]uril-based containers and viologen guests as key building elements. Cucurbit[n]urils (CB[n], n=5-10) are fascinating hosts forming a wide range of inclusion complexes (caviplexes) with 4,4'bipyridinium salts, known as viologens, either as discrete 1:1 inclusion compounds with $\mathrm{CB}$ [7] or as ternary inclusion compounds involving two hosts or two guests (2:1) with CB[7], and (1:2 or $1: 1: 1$ ) with $\mathrm{CB}[8]$. This property is currently being actively exploited to design and prepare self-assembled dynamic stimuli-responsive supramolecular polymers including gels, vesicles, films and organized arrays of polymeric microspheres or nanoparticles. This reviews highlights the main benefits of such polymers and gives an overview of the achievements and progresses made in this field over the past decades.
\end{abstract}

Keywords : Viologens, cucurbit[n]urils, polymers, self-assembly, films, gels, nanoparticles 
1. Introduction 2

2. Soluble supramolecular assemblies 3

a. Basics of viologens insertion in cucurbiturils 3

b. Rotaxane-like polymers 5

c. Stimuli-responsive supramolecular assemblies. $\quad 7$

3. Towards dynamic supramolecular materials 13

$\begin{array}{ll}\text { d. Vesicles } & 13\end{array}$

e. Hydrogels. 15

f. Films, superlattices and nanoparticles 19

4. Conclusion 23

5. References 25

\section{Introduction}

Supramolecular assemblies are ubiquitous in living systems. The best known example is most probably DNA, wherein simple molecular building blocks are organized into functional structures via a complex network of orthogonal ${ }^{1}$ non covalent bonds. ${ }^{2}$ In more general terms, biologically relevant supramolecules have been an endless and exciting source of inspiration for designing self-assembled supramolecular polymers with tailored structural, dynamic and functional features. Fortunately enough, the supramolecular toolbox available to address these challenging issues contains a wide variety of noncovalent interactions, varying in directionality and strength, from weak dipole-dipole attractive forces to highly directional hydrogen bonds and strong electrostatic ion-ion and ion-dipole interactions. The unique properties and the main advantages of supramolecular polymers as compared to classical covalent polymers rely on the reversible and dynamic nature of the interactions involved in their construction. This key feature has inter alia opened up exciting opportunities for the development of stimuli-responsive, self-healing or self-adjusting materials. All these aspects have already been covered in many excellent review articles, to which the reader is referred for further information, focusing either on the preparation or on the properties of supramolecular polymers. ${ }^{3-7}$ 
The scope of this review is not to provide one more overview on supramolecular polymers but rather to point outthe strategies which have been implemented to promote the formation of self-assembled supramolecular polymers from cucurbit[n]uril ( $C B[n])$ hosts and viologen guests, used as key building elements. The first part focuses on the inclusion of viologens in $\mathrm{CB}[\mathrm{n}]$ and provides an overview of the polymeric systems reported in literature involving these two components. The second part is dedicated to the applications of these specific host-guest processes in "soft-material" science, most notably to provide access to vesicules, hydrogels and hybrid nanoparticule-containing systems.

\section{Soluble supramolecular assemblies}

\section{a. Basics of viologens insertion in cucurbiturils}

1,1-Di(hydrocarbyl)-4,4'-bipyridinium salts, best known as Viologens $\left(\mathrm{V}^{2+}\right){ }^{8}$ exhibit unique redox and chemical behaviors which have proved highly valuable to the construction of functional molecular materials, ${ }^{9}$ including for applications in organic electronics, organic batteries and for the development of molecular machines. Viologen derivatives are for instance commonly used as electron poor components in donor-acceptor type host- guest complexes, as seen in Stoddart's works on "blue-box"-based rotaxane and catenanes. ${ }^{10-12}$ From an electrochemical point of view, these dicationic compounds are subject to two consecutive Nernstian electron transfers ${ }^{13}$ attributed to the successive formation of the cation-radical $\mathrm{V}^{\bullet}$, and neutral quinonic forms $\mathrm{V}^{0}$. The growing interest for viologen derivatives in supramolecular chemistry over the past decades thus mainly stems from the acceptor properties of the dicationic $\mathrm{V}^{2+}$ " ground" state and from the stability of the radicalcationstate ${ }^{14} \mathrm{~V}^{+\bullet}$ which can both be implemented for the construction of supramolecular assemblies. ${ }^{10-12,15,16}$

Cucurbit[n]urils (CB[n]s) represent a specific class of barrel-shaped cavitands made of $n$ glycoluril moieties connected by methylene bridges. ${ }^{17,} 18$ They are compatible in size with cyclodextrins, and the nature of their cavity (in terms of solvophobicity) are similar, but CB[n]s are more stable towards temperature and aggressive chemical environments. $\mathrm{CB}[\mathrm{n}] \mathrm{s}$ are also not toxic, cheap and resistant to microorganisms, which makes them excellent candidates to replace cyclodextrins for most applications. Our own contribution to this field includethe stabilization of reactive species and drug carriers, ${ }^{19-22}$ use of $\mathrm{CB}[\mathrm{n}]$ as structural elements in 
hybrid composites, ${ }^{23,} 24$ as template for nanoparticle synthesis, ${ }^{25,}{ }^{26}$ or to develop special catalysts and coatings, ${ }^{27,} 28$ sensors ${ }^{29}$ and speciality polymers. ${ }^{23}$ Their ability to host a wide range of substrates is mainly due to the hydrophobicity of the inner cavity lacking hydrogen bond donors/acceptors moieties. From a thermodynamic point of view, the exceptionally high affinity of $\mathrm{CB}[\mathrm{n}] \mathrm{s}$ for positively charged organic guests in water is attributed to a combination of factors including the desolvation of the guest, the ejection of " high energy " water molecules trapped inside $\mathrm{CB}[\mathrm{n}] \mathrm{s}$ prior to encapsulation, and to ion-dipole interactions between the carbonyl functions at the cavity portal and any positively charged parts of the guest. In most cases only one guest can be fitted within the cavity of the smallest CB[n] $(n=5,6,7)$ while the larger cavity of $\mathrm{CB}[8]$ can potentially accommodate two or even three guests. $^{30-35}$

As a matter of fact, most efforts in the field of supramolecular chemistry have focused on $\mathrm{CB}[8]$, on account of its ability to accommodate two $\pi$-conjugated guests tightly interacting inside the barrel-shaped cavity in the form of cofacial charge transfer complexes. ${ }^{36}$ The opportunities are conversely more limited for the smallest analogs $\mathrm{CB}[5], \mathrm{CB}[6]$ and $\mathrm{CB}[7]$, whose inner cavities only allow to host single guests. Another key aspect of $C B[n] s$ is their exceptionally strong affinities for a wide range of cationic or even neutral guests in aqueous media, with binding constants among the largest ever reported for host-guest complexes, reaching $10^{17} \mathrm{M}^{-1}$ for $\mathrm{CB}[7]$ and diamantane. ${ }^{37}$ The most common Host-Guest (HG) complexes formed with $\mathrm{CB}[\mathrm{n}]$ and viologens are shown in Figure 1. The size, structure and symmetry of viologen derivatives, together with their dicationic nature, make them perfect guests for $C B[7$ or 8], forming very stable caviplexes (Figure 1a) with binding constants as high as $5 \times 10^{4} \mathrm{M}^{-1}$ with $\mathrm{CB}[7]$ and $1.1 \times 10^{5} \mathrm{M}^{-1}$ with $\mathrm{CB}[8]$ in water at $25^{\circ} \mathrm{C} .{ }^{38,39}$ The major driving force for the formation of such caviplexes seems to be strong ion-dipole interactions between the cavitands occulli and the positive charges of the guest. $\mathrm{CB}$ [8] can even accommodate two viologen cation radicals to yield the dicationic 1:2 caviplex depicted in Figure $1 \mathrm{~b}$, wherein charge repulsion is lowered by the one-electron reduction of each viologens. This homo-valent complex involving extensive orbital overlaps between two viologen cation radicals is known as a $\pi$-dimer. ${ }^{16,40-43}$ Then, ternary hetero-caviplexes(1:1:1) are also frequently observed with $\mathrm{CB}[8]$; the latter case being illustrated in Figure $1 \mathrm{c}$ with a $\mathrm{CB}[8]$-stabilized charge transfer complex between a dimethylated viologen and an electron-rich dihydroxynaphthalene. ${ }^{44}$ 


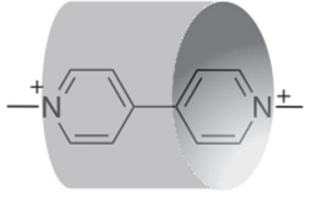

a

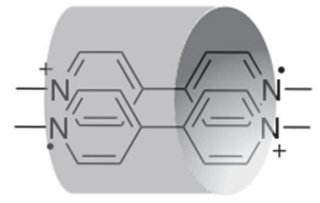

b

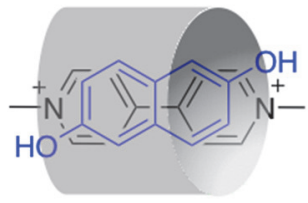

C

Figure 1: Selected examples of $C B[7,8]$ methyl-viologen caviplexes: a) $\left.\left.M V^{2+} @ C B[7] ; b\right)\left(M V^{+}\right) 2 @ C B[8] ; c\right) M V^{2+} . D H N @ C B[8]$.

\section{b. Rotaxane-like polymers}

Many examples of pseudo-rotaxane-like oligomers and polymers incorporating a rod-like guest and cyclic ring-like hosts held together by noncovalent forces are found in literature. ${ }^{45}$ The prefix pseudo used here, refers to the absence of stoppers on both ends of the molecular axle, which implies that the $\mathrm{CB}[\mathrm{n}]$ wheels are free to move out. Such pseudorotaxanes have been obtained by self-assembly of different viologens-based polymers/oligomers with $\mathrm{CB}[\mathrm{n}]$. The main strategies investigated so far involve either $\mathrm{CB}[6]$, $\mathrm{CB}[7]$ or $\mathrm{CB}[8]$ wheels threaded on linear viologen-based oligomer/polymer strings (Figure $2 \mathrm{a}),{ }^{46,47}$ on dendrimers ${ }^{48}$ or on branched polymers(Figure $2 \mathrm{~b}$ ). ${ }^{49,50}$

a)

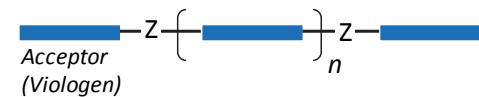

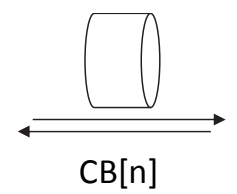

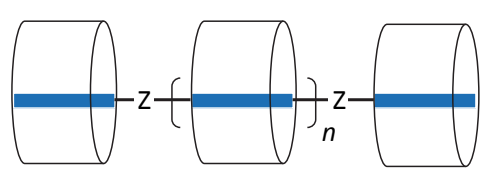

b)
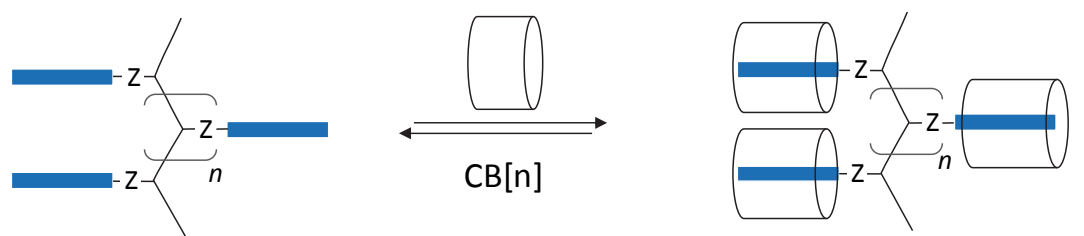

Figure 2. Threading $C B[n] s$ on linear or on branched polymer backbones.

With $\mathrm{CB}[8]$, the large size of the inner cavity enables to stabilize a wide range of $\pi$-conjugated donor-acceptor pairs. This specific feature has been exploited to develop different elongation approach sketched in Figure 3, aiming at extending the length of polymer backbones. The most straightforward strategy relies on a $\mathrm{CB}[8]$-promoted self association of two identical or two different polymers bearing either a $\pi$-acceptor (viologen-based) or a $\pi$-donor (naphatalene-based) pendant guest (Figure 3a). Formation of a host-stabilized charge-transfer complex between those two units opens the way towards either homo- (P1=P2) or heteroextended polymers $(\mathrm{P} 1 \neq \mathrm{P} 2) .{ }^{51} \mathrm{~A}$ similar strategy has been implemented to provide access to 
a supramolecular protein/polymer conjugate involving bovine serum albumin and a poly(ethylene glycol)-based polymer. ${ }^{52}$ The name of « supramolecular handcuff » has been put forward to describe such system that ties together two different (macro)molecular units with reversible and non-covalent bonds. ${ }^{52}$

a)

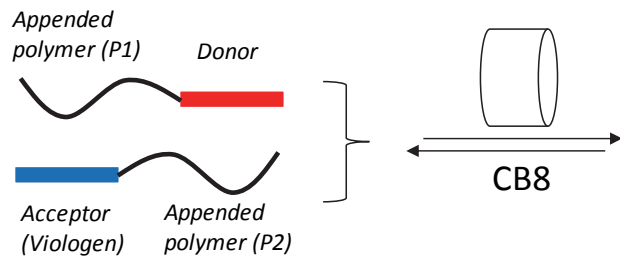

b)

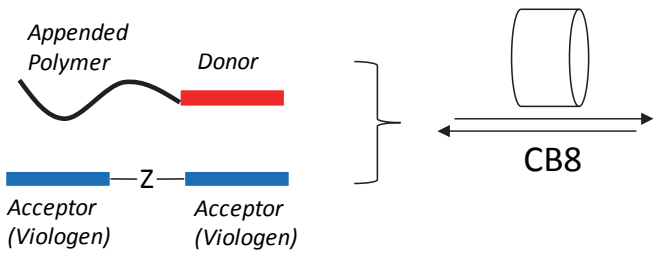

c)
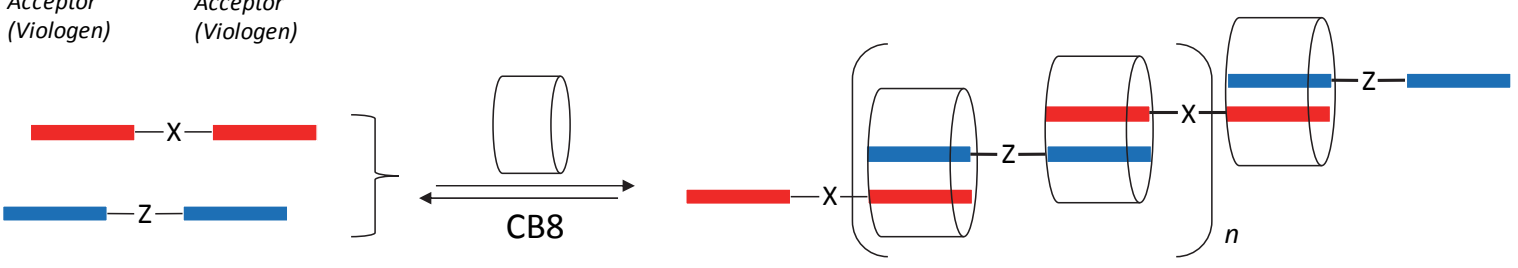

d)
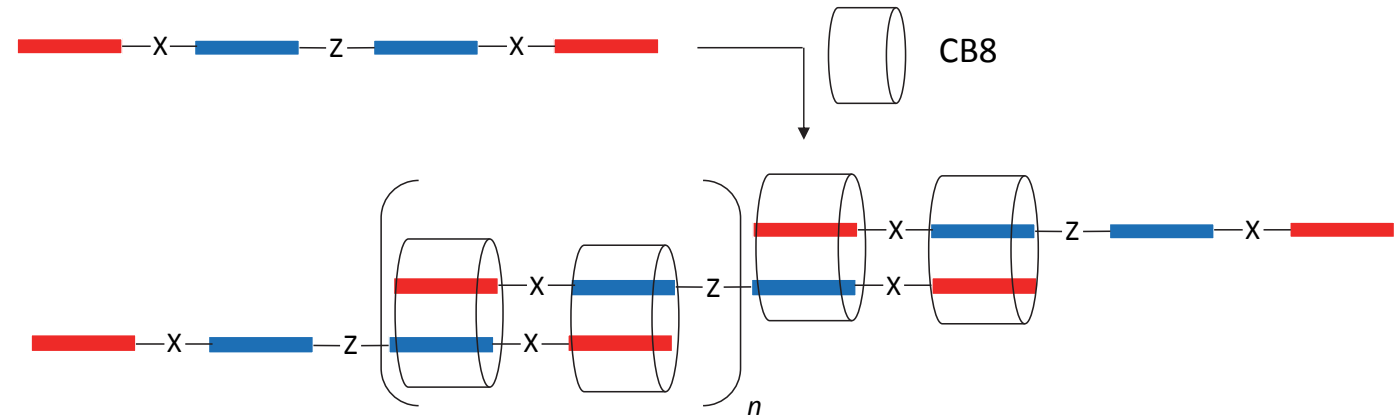

Figure 3. Schematic representation of the threading and elongation strategies developed with viologen-based polymers.

A variation of this method has been developed to link two identical donor-appended polymers with a bis-viologen spacer (Figure $3 \mathrm{~b}$ ). In the presence of $\mathrm{CB}[8]$, a naphtolterminated PEG chain (Donor block) and a low molecular weight bis-viologen guest (Acceptor block)were found to form discrete supramolecular DAD triblock copolymers. ${ }^{53}$ The authors have also shown that DOSY NMR and solution viscometry can advantageously be used to probe the self-assembly process in aqueous media. ${ }^{54}$ The supramolecular polymerization of DAAD type monomers (azobenzene-viologen-viologen-azobenzene, compound $\mathbf{1 2}$ in Figure 5) with $\mathrm{CB}[8]$ has also been reported (Figure $3 \mathrm{~d}$ ). ${ }^{55}$ The molecular weight and the 
polydispersity of the supramolecular polymers grown by iterative complexation of the viologen/azobenzene/CB[8]units depends on the relative molar ratio of the monomers involved in the self-assembled architecture and on the $Z$ vs $E$ geometry of the azobenzene photoisomarizable moieties. ${ }^{55}$

A supramolecular " bottlebrush » polymer hasbeen constructed similarly from rigid AA and DD type monomers in water (Figure $3 c$ and Figure 4). The self-assembled supramolecular polymer formed in the presence of $\mathrm{CB}[8]$ has been mainly characterized by DLS and DOSY NMR. ${ }^{56}$

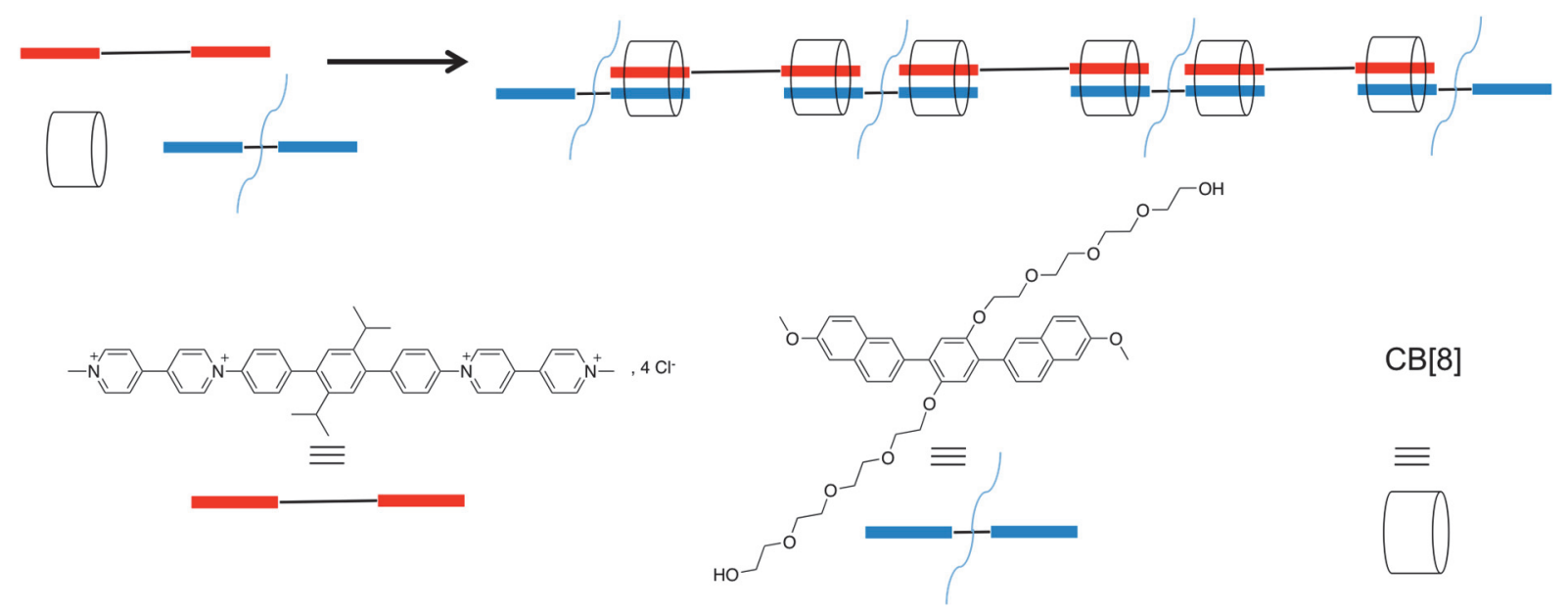

Figure 4: Supramolecular « bottlebrush » polymer constructed from rigid AA and DD type monomers. ${ }^{56}$

\section{c. Stimuli-responsive supramolecular assemblies.}

The ability to control the organization of molecules within molecular materials has emerged in the past decade as a major scientific objective that is mainly motivated by exciting foreseeable applications in areas ranging from electronics to medicine. Enormous technologic interests are indeed at stake in being able to control and exploit the properties of dynamic self-assembled materials built from monomers and held together by reversible and directional interactions.

The arrangement/organization within supramolecular assemblies built from viologens and CBs can potentially be modulated with chemical, photochemical and electrochemical stimuli. ${ }^{57}$ The redox properties of viologens and the ability of $\mathrm{CB}[8]$ host to promote the $\pi$-dimerization of viologen cation radicals ${ }^{10,12,58-61,62,63}$ are particularly suited to this purpose. $\pi$-dimers is the commonly accepted trivial denominations designating sandwich-like, multicenter-bonded, 
dimeric entities featuring sub Van der Waals (VdW) intra-dimer separation distances. In $\pi$ dimers, the non-covalent "chemical bonding" arises from the orbital overlaps occurring between two identical cation radicals. Another salient feature of $\pi$-dimers is their metastable character inherent to the weakly stabilizing bonding term that is hardly sufficient to counterbalance the Coulombic repulsion arising between both positive charges. As a matter of fact, the vast majority of $\pi$-dimers reported so far in literature involves intermolecular overlaps imposed either at the solid state by packing effects or favored in solution by the use of unusually high concentrations of radicals. To cope with this problem, one strategy which has proved quite effective in promoting the formation of non covalent long-bonded dimers in standard temperature and concentration ranges, relies on the use of container molecules, such as the cyclodextrins or cucurbit[n]urils, capable of hosting and stabilizing such selfassembled dimeric entities. ${ }^{64,65}$
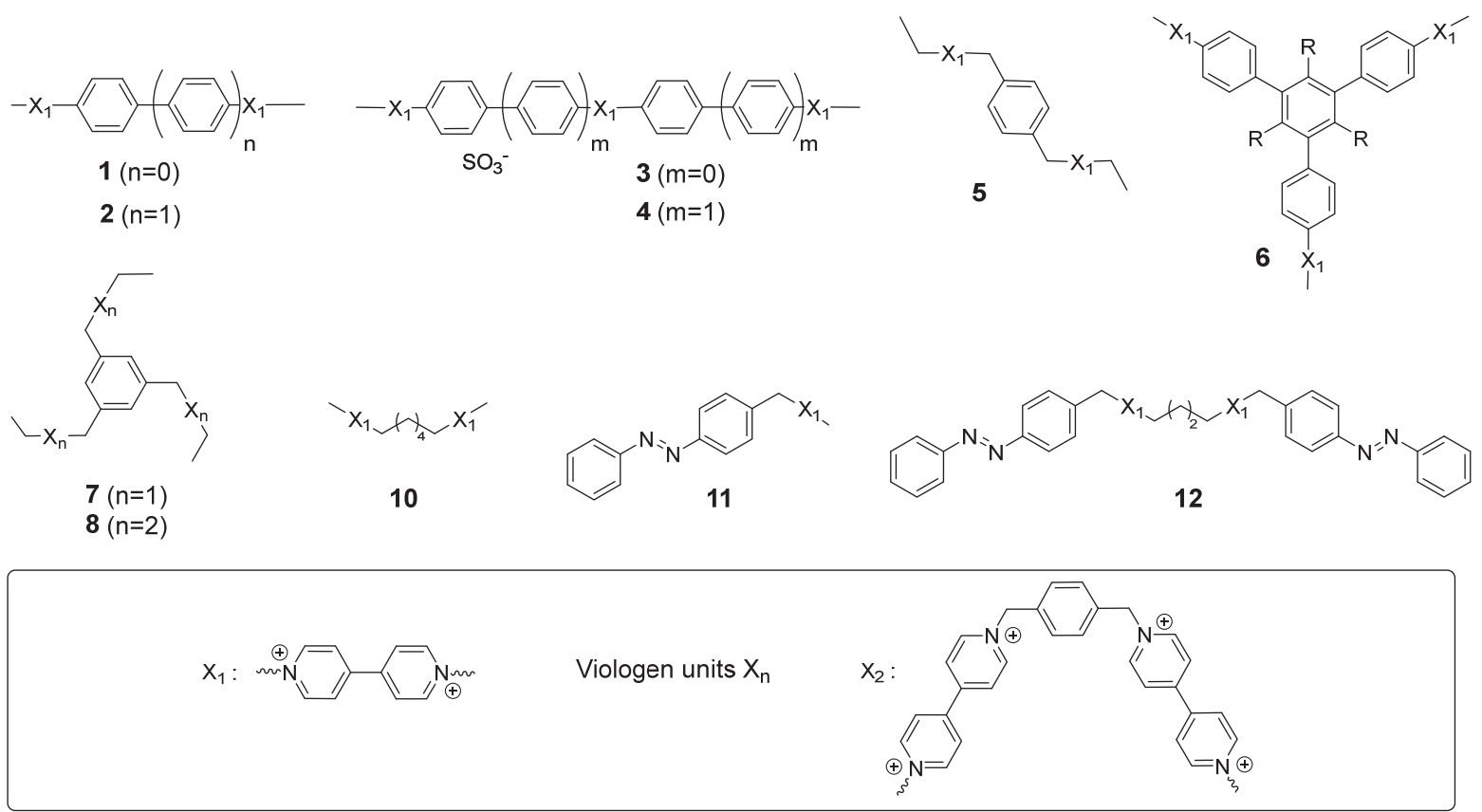

Figure 5. Viologen-based building blocks used for the construction of stimuli-responsive supramolecular polymers.

A mere handful of articles have been reported so far on stimuli-responsive supramolecular systems involving viologen and CBs as key building elements. In most cases, formation of $1 \mathrm{D}$ or $2 \mathrm{D}$ polymers rely on the intermolecular $\pi$-dimerization of two viologen cation radicals within the cavity of a $\mathrm{CB}[8]$ host. The self-assembly process, i.e. formation of the polymer, is thus triggered by chemical reduction of the viologen units. Another key point is the dimensionality of the self-assembled materials produced upon reduction. The latter is in fact determined by the structure of the viologen-based monomer: 1D linear polymers have been 
obtained from rigid bis-viologen compounds featuring linear structure (1-4 in Figure 5) while 2D networks could be obtained from star shaped building blocks featuring at least three viologen units (6-8 in Figure 5).

The groups of Li and Zhao have reported beautiful examples of redox-switchable assemblies built from a series of linear $\pi$-conjugated compounds incorporating two or three viologens connected through phenyl or bi-phenyl linkers (1-4 in Figure 5). ${ }^{66}$ They first found that these oligomers spontaneously self-assemble in aqueous media, even in quite diluted conditions $\left(5 \times 10^{-4} \mathrm{M}\right)$, upon addition of sodium dithionite, used as a reducing agent, to form linear $1 \mathrm{D}$ polymers. They have also established that the $\pi$-dimer-based self-assembly proceeds even more efficiently in the presence of one molar equivalent of $C B[8]$. The aggregation of the $1 D$ polymers into bundles was also proposed to account for the micrometric diameter of linear molecular wires visualized by cryo-transmission electron microscopy (Figure 6).

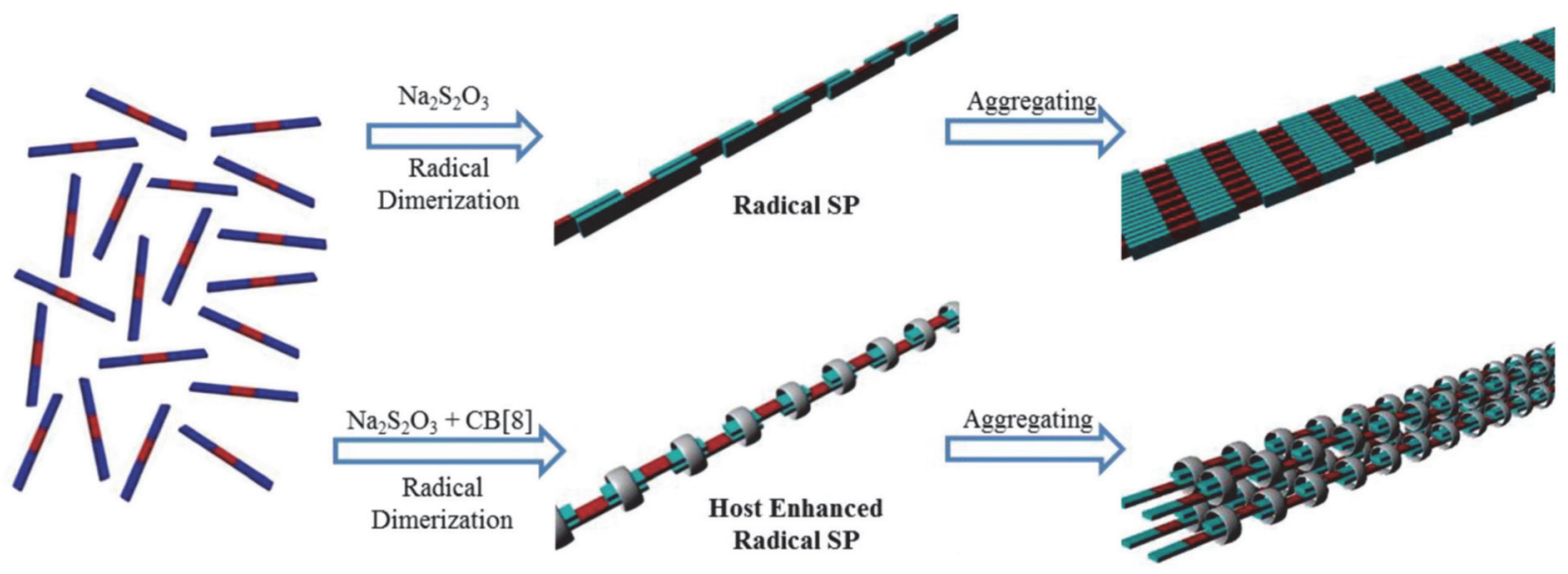

Figure 6. Cartoon representation of the rigid linear 1D-polymer structures generated upon reduction of 1 or 2 in thepresence or in the absence of $\mathrm{CB}[8] .{ }^{66}$

A similar procedure applied to the star-shaped monomer 6 led to the formation of single layer honeycomb-like 2D networks whose structure wasput forward on the ground of AFM, DLS and SAXD data. ${ }^{67,68}$ Here again, addition of $\mathrm{CB}[8]$ was only found to improve the efficiency of the self-assembly process relying on the intermolecular $\pi$-dimerization of the chemically reduced viologen units.

Another redox-responsive 2D supramolecular framework has been reported by the group of Kathiresan ${ }^{69}$ upon studying a series of flexible star-shaped poly-viologens (5, 7, 8 in Figure 5). Reduction of the latter compounds with sodium dithionite led to the formation of $\pi$-dimerized species revealed by UV-Vis absorption measurements. As in previous cases, addition of CB[8] 
was only found to improve the efficiency of the self-assembly process as a result of the additional stabilization of the intermolecular dimer within its hydrophobic cavity. As a general statement, it should be noted that the formation of such $2 \mathrm{D}$ arrays is quite difficult to demonstrate in an unambiguous way and the proposed arrangement in the aforementioned examples remains unfortunately quite speculative.

A redox-triggered assembly/disassembly of a 1D supramolecular polymer built from the bis(psulfonatocalix[4]arene) $9, \mathrm{CB}[8]$ and the hexamethylene bridged bis-viologen10, has been reported by Liu and co-workers (Figure 7)..$^{70}$

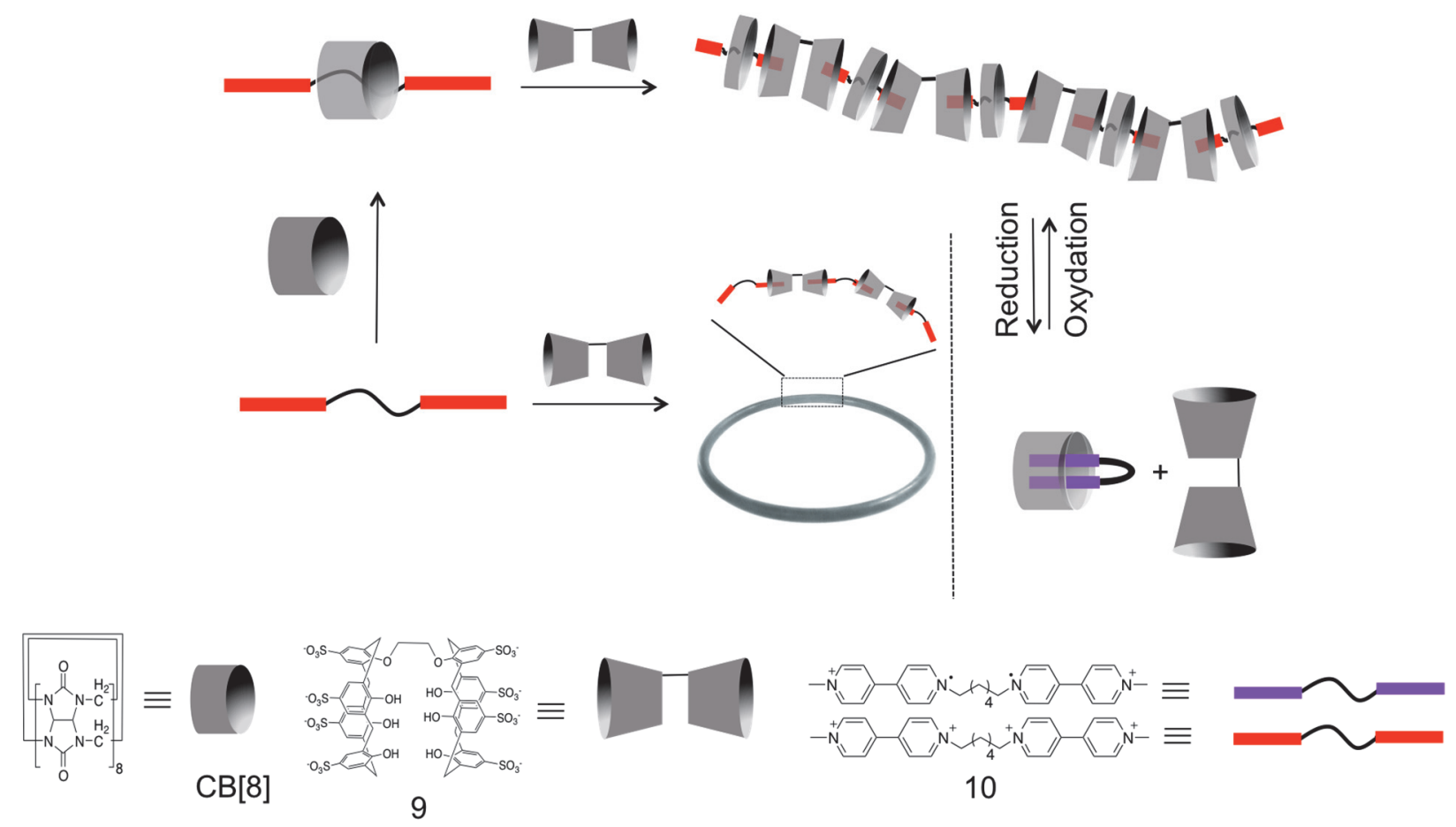

Figure 7. Schematic representation of the CB[8]-based self-assemblyand of the effect of redox stimulation. ${ }^{70}$

The authors found that the cyclic self-assembled oligomers produced from $\mathbf{9}$ and $\mathbf{1 0}$ can be converted into linear polymers upon addition of $\mathrm{CB}[8]$, the latter playing a key role in the rigidification of the bis-viologenguest through the formation of the $10 @ \mathrm{CB}[8]$ rotaxane-like inclusion complexes. The 1D structure of the self-assembled ternary polymer ismainly supported by AFM measurements revealing the observation of linear nanostructures whose diameter seems in agreement with the size of the $\mathrm{CB}$ [8] host. Reduction of the viologen units embedded in the polymer backbone with an excess hydrazine was then found to trigger a dissociation of the linear supramolecular assembly, the driving force of the disassembly being the stabilization of a viologen radical $\pi$-dimer inside the cavity of $\mathrm{CB}[8]$. 
Light has also been successfully used to trigger the association/dissociation of CB[8]-mediated viologen-based supramolecular polymers. ${ }^{71-73}$ Del Barrio et al. have established that the $E$ isomer of the viologen-based guest $\mathbf{1 1}$, bearing a photo-responsive azobenzene moiety, selfassembles into 1D polymers, both in solution and at the solid state. The X-ray structure of the linear supramolecular polymer isolated from $\mathrm{CB}[8]$ and 11 is shown in Figure 8 . Another key finding is that depolymerization occurs upon photoisomerization of the guest $(E \rightarrow Z)$ with UV light, as revealed by DOSY, small angle neutron scattering and static light scattering experiments. Similar results have been obtained with the bis-viologen derivative 12.

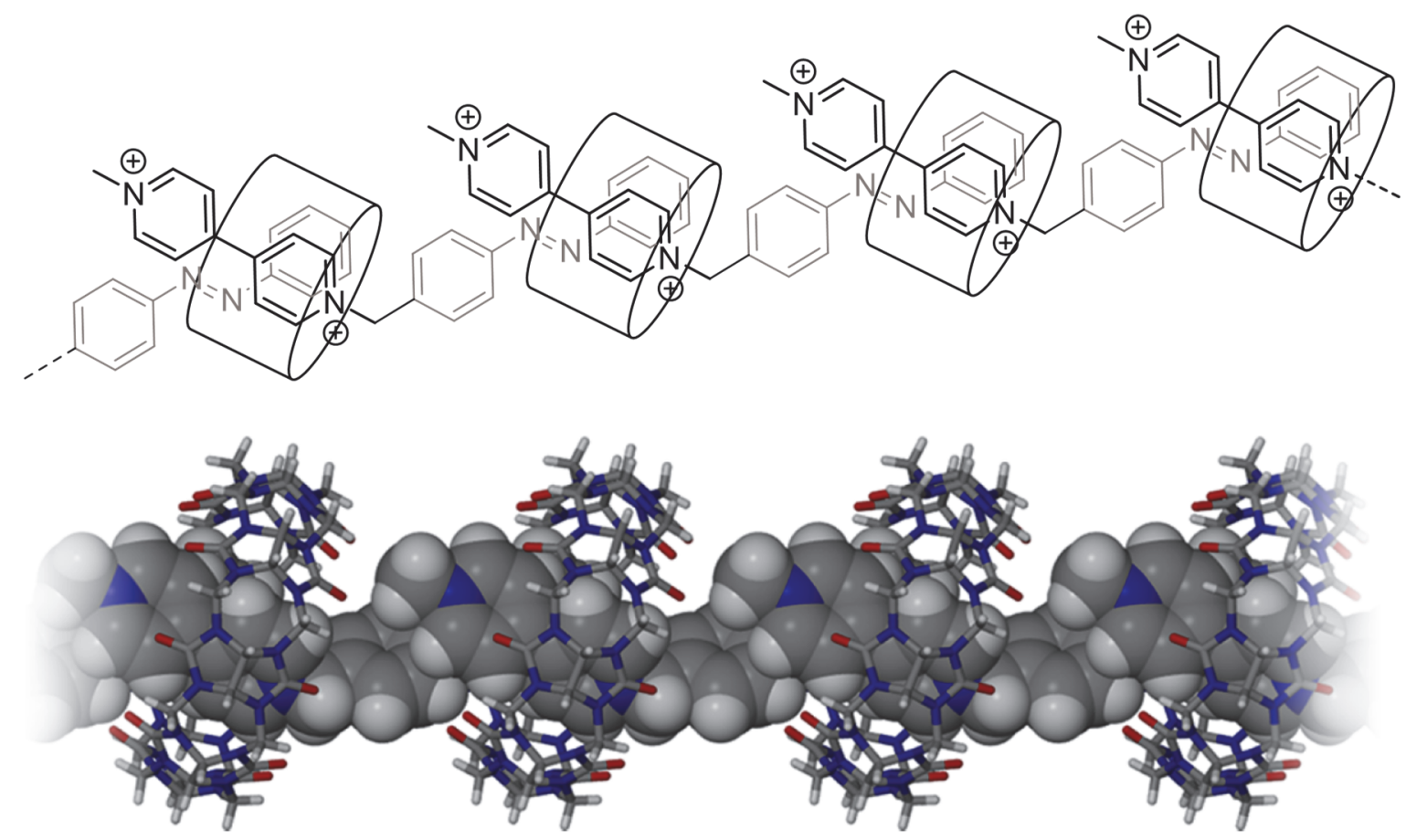

Figure 8. Schematic representation and side view of the X-ray structure of the linear supramolecular assembly obtained from11 (Z isomer) and $C B 8 .{ }^{71}$

Following a similar approach, a photo-responsive supramolecular hyperbranched polymer has been obtained by self-association of the star-shaped compound 13 , incorporating an azobenzene unit and a viologen moiety on each branch (Figure 9). ${ }^{73}$ As seen in the previous case, the assembly relies on the formation of host-stabilized charge-transfer complexes between the viologen units and the diazobenzene fragment behaving as the electron-rich donor fragment. The self-assembly and the morphology of the branched polymer could be tuned chemically, with the relative ratio of 13 and $\mathrm{CB}[8]$ introduced in solution, and by light, upon triggering the isomerisation of the diazobenzene moieties. 


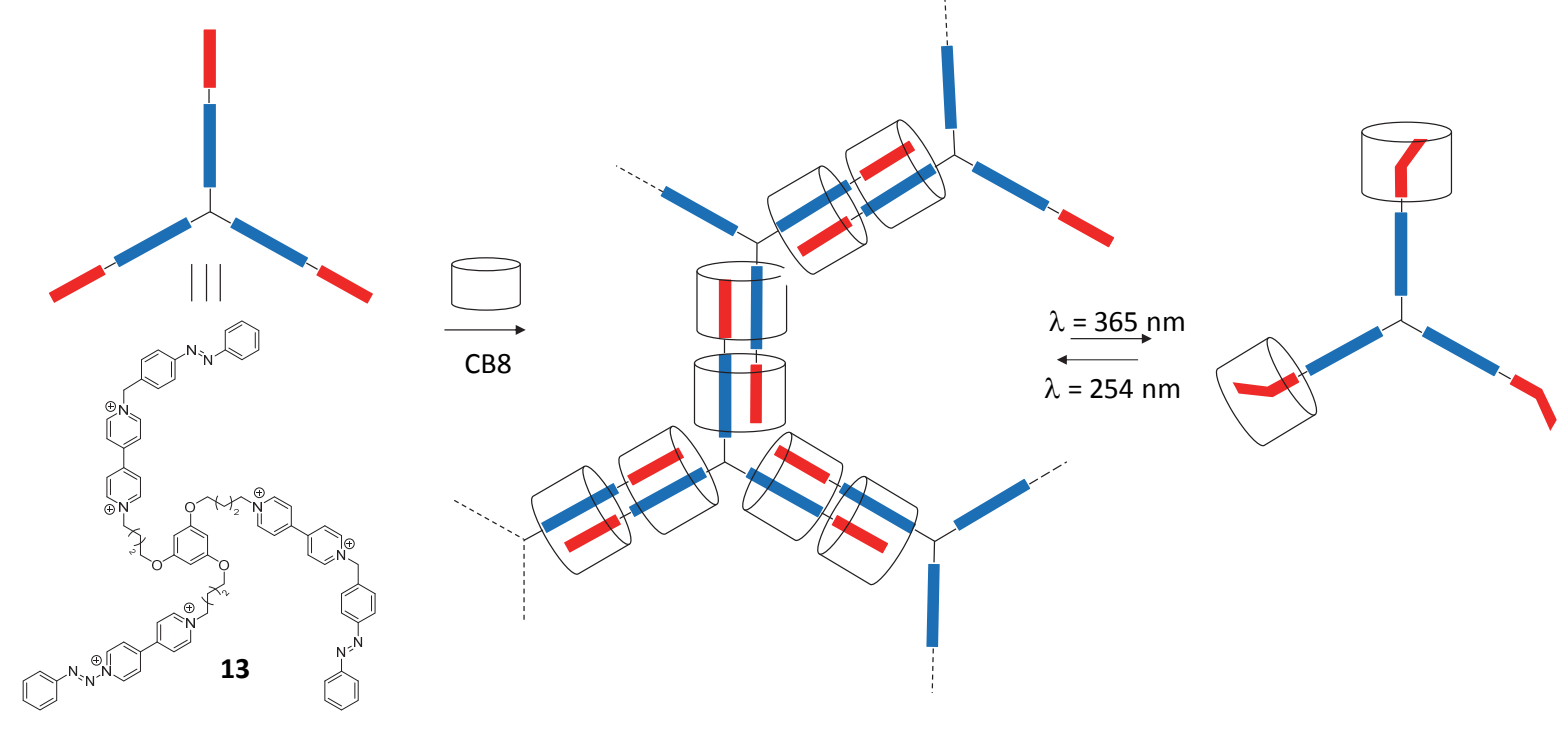

Figure 9.Schematic representation of the sel-assembly process proposed with the star-shaped monomer 12 with CB[8]. ${ }^{73}$

Literature gives also a few examples of covalent polymers decorated by pendant peripheral organic groups using the affinity of cucurbiturils hosts for viologens. This approach is illustrated in Figure 10 with a CB[8]-promoted non-covalent grafting of $\alpha$-manosidesubstituted viologens onto a 2-naphtol appended methacrylate copolymer (Figure 10). ${ }^{74}$ Selfassembly relies here on the formation of a stable host-guest complex between the viologen and naphtalene-based recognition units within the cavity of $\mathrm{CB}[8]$. The authors found that the latter complex, and hence the whole self-assembled system, can be fully dissociated bychemical reduction of the viologen moieties. They also report that the viologen appended polymer can be further self-assembled using the strong affinity of the pendant glycol for lectin (ConA), the formation of a supramolecular cross-linked network being mostly revealed by turbidity measurements.

We have focused in this section on fully soluble stimuli-responsive supramolecular polymers. Consideration must also be given to responsive assemblies involving formation/dissociation of vesicles or nanoparticle-containing assemblies. These specific studies will be discussed in the following paragraphs concerning dynamic supramolecular materials. 

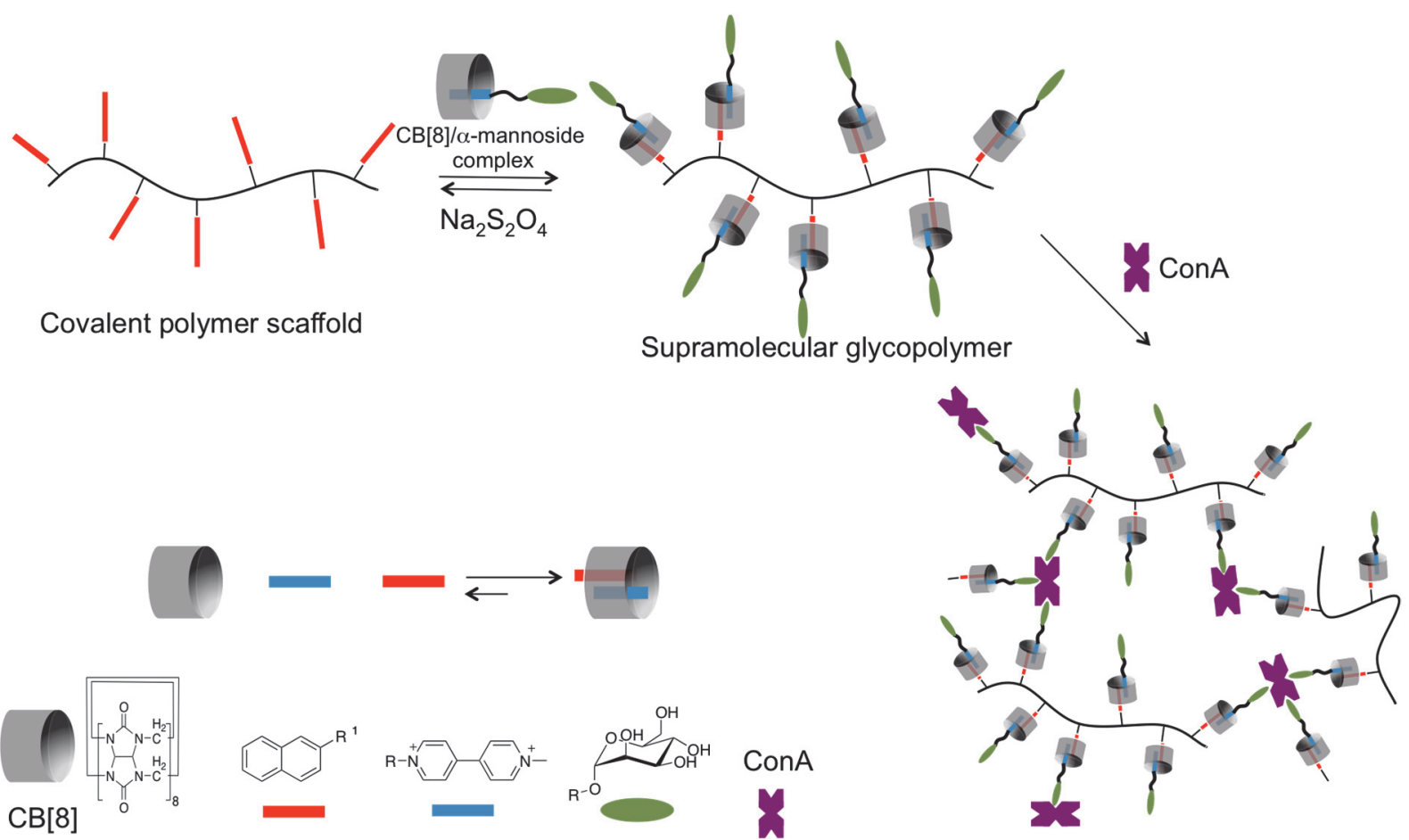

Figure 10. a) Reversible Formation of aviologene/CB[8]- glycopolymer conjugate and b) self-assembly of the glycopolymer with a monosespecific lectin (concanavalin A). ${ }^{74}$

\section{Towards dynamic supramolecular materials}

\section{a. Vesicles}

The host-guest ternary complexation between $\mathrm{CB}[\mathrm{n}] \mathrm{s}$, viologens and amphiphilic molecules can be used to tune the surface properties of cell membrane models. This strategy has been implemented to enhancethe affinity for specific molecules without interfering in the biologic functions of the cells. Cavatorta et al. have successfully used CB[8] hosts to immobilize blood cells on a methyl viologen-functionalized supported lipid bilayer. Cells have been found to specifically assemble on the bilayer through multivalent interactionsonly when $\mathrm{CB}$ [8] was present to drive the formation of ternary complexes. ${ }^{75}$ Supramolecular assemblies beetween $C B[n] s$ and viologens have also found interesting application in the fields of biomaterials and of nano-medicine. Vesicles and micellesmodified with amphiphilic selfassembled structureshave indeed been used to deliver bioactive molecule inside cells or to enhance specific biological responses. ${ }^{76,77}$ Such vesicles have been successfully employed to encapsulate fibroblast growth factor, extending its bioactivity without the necessity of excipients such as heparin. ${ }^{78}$ Hetero-ternary complexes involving the host-guest $\mathrm{CB}$ [8]-maleimide-modified methyl viologen (MV) and azo-dyes have beenself-assembled on the surface of giant vesicles to 
be used as models of optically active drug carriers for delivery to specific targets. ${ }^{79-81}$ On the other hand, Das and co-workers have established that different aromatic amino acids can form vesicles through ternary complexes with $\mathrm{CB}[8]$ and an amphiphilic viologens. They also report that vesicle formation is a peptide dependent process; with tryptophan forming stable vesicles while tyrosine and phenylalanine failing to do so. ${ }^{82}$ Vesicles generated from adiazobenzenecontaining peptide have been shown to be tunable by a number of external triggers including the trans-cis isomerization of the azobenzene group upon irradiation with UV-light of $365 \mathrm{~nm}$. The Z/E photoisomerization was also shown to trigger the breakdown of the ternary complex and eventually to the disruption of the vesicle (Figure 11). ${ }^{82}$

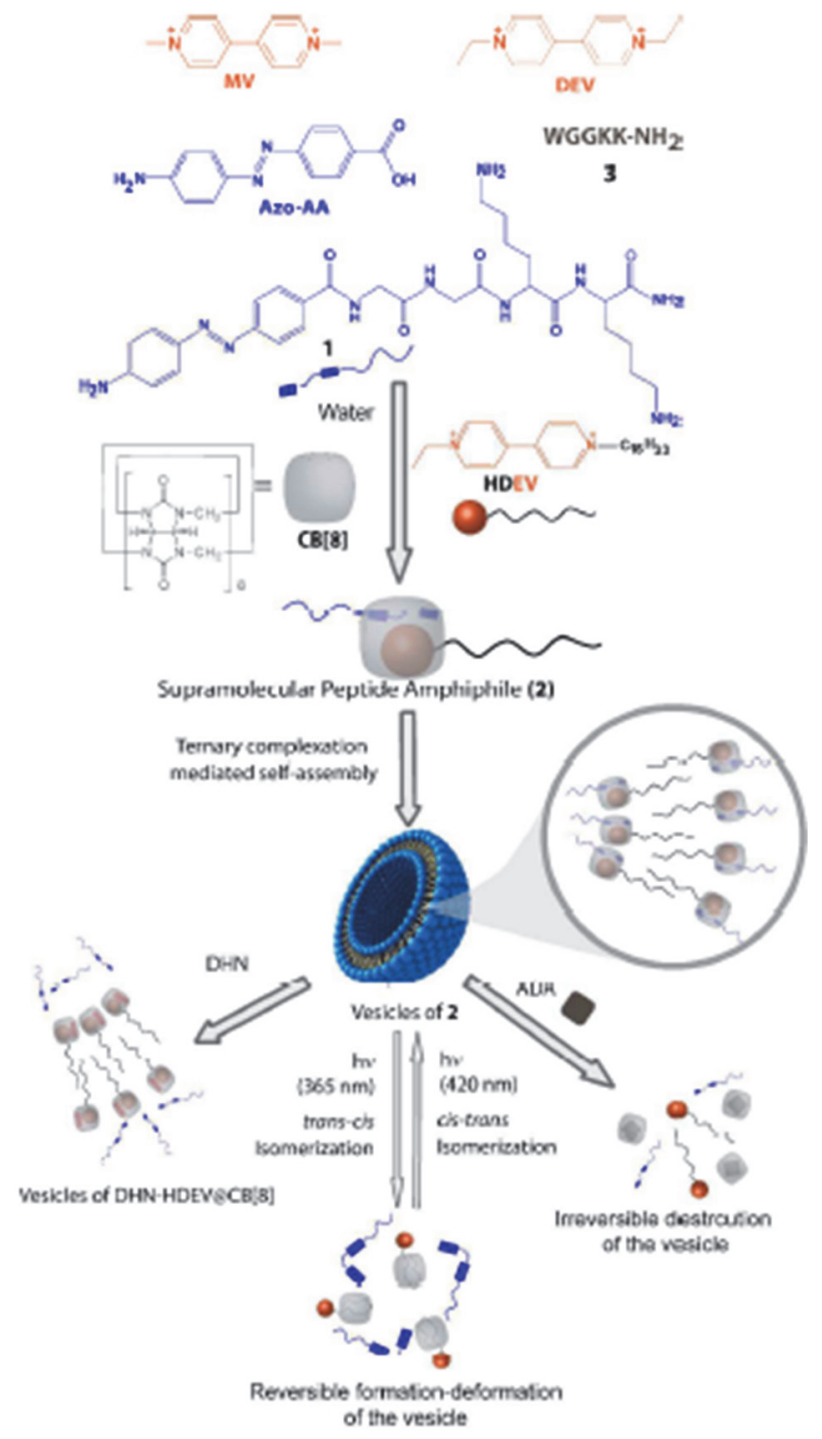

Figure 11. Chemical structures of Azo-AA ((E)-4-((4-aminophenyl)diazenyl)benzoic acid), DEV ( $N, N^{\prime}$-diethylviologen dibromide), HDEV ( $N$-ethyl-N'-hexadecylviologen dibromide), and CB[8], pictorial presentation of the formation of supramolecular peptide amphiphiles(SPA)and its vesicle as well as responses to various stimuli. ${ }^{82}$ 


\section{b. Hydrogels.}

Self-assembly of $C B[n]$ with viologens has been found, in certain circumstances, to foster the formation of hydrogels. Supramolecular hydrogels ${ }^{83,84}$ are hydrophilic polymeric networks constructed from molecular monomers connected together through highly directional and reversible noncovalent interactions. The dynamic nature of these intermolecular bonds provides many fascinating characteristics including easy processability, reversibility, selfhealing, and stimuli-responsiveness. Biocompatible hydrogels made from the cross-linking of biopolymers such as the polysaccharides also open exciting perspectives in biomedicine, food and cosmetic technology. ${ }^{85}$ The supramolecular character of the polymerization, while avoiding cross-linkers and limiting the numbers of reaction steps, makes the process more biocompatible, biodegradable and sustainable.

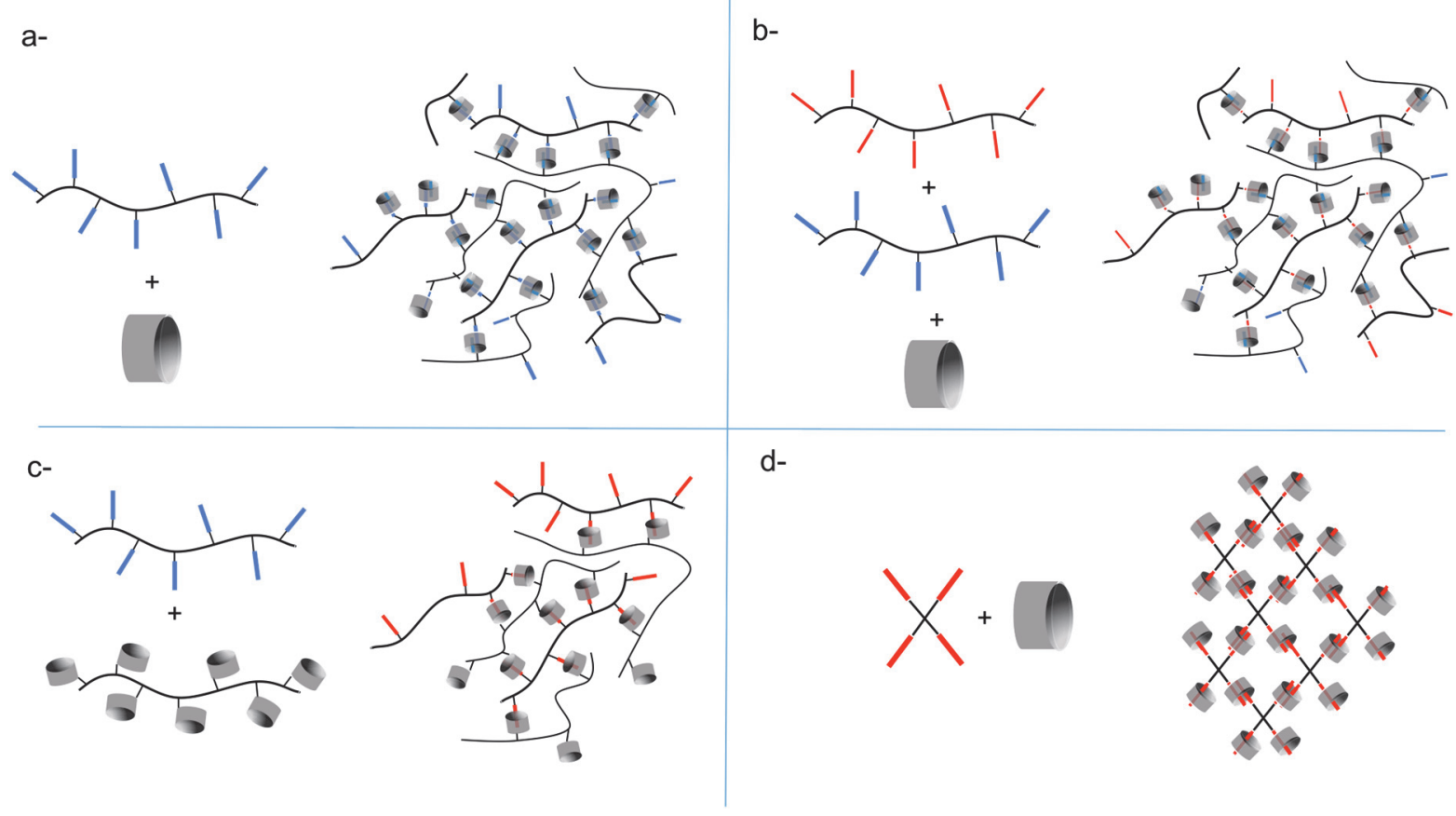

Figure 12: Four different patterns involved in the hydrogelation of CB[8]/viologen-based supramolecular assemblies.

$\mathrm{CB}[8]$ has been shown to trigger the formation of hydrogels through the formation of entangled supramolecular assemblies. Most $\mathrm{CB}[\mathrm{n}]$-based hydrogels reported so far in litterature do not involve viologens as guests. Recent examples include polysaccharides based on hyaluronic acid or cellulose functionalized with pendant cysteine-phenylalanine dipeptides $^{86}$ or $\mathrm{N}$-(4-diethylaminobenzyl) branched chitosan ${ }^{87}$ forming stable gels upon addition of $\mathrm{CB}[8]$. In the latter case, gelation results from the 2:1 host-guest binding mode depicted in Figure 12a. The large affinity between adamantine and $C B[7]$ has also been used 
recently ${ }^{88}$ to promote an effective cross-linking between two pendant $\mathrm{N}, \mathrm{N}$-dimethyl acrylamide based polymers bearing either $\mathrm{CB}[7]$ or adamantine substituents (Figure 12c). The different patterns encountered in literature are sketched in Figure 12.

Hydrogels involving viologens as guests have been obtained through the strategy depicted in Figure 12b. Scherman and coll. pioneered this approach in 2010 upon publishing the first example of hydrogels built from $\mathrm{aCB}[8]$-mediated association of two copolymers functionalized either with viologen-based acceptors or naphthalene-based donors. ${ }^{89}$ The resulting 1:1:1 supramolecular ternary complexes ( $\mathrm{CB}[8]$ /viologen/naphtoxy) proved particularly efficient to control the gelation kinetics, the cross-linking density and the properties of the material. This approach was further developed to optimize the formation, stability and properties of hydrogels obtained from (vinylbenzyl)trimethylammonium (positively charged) or styrene sulfonate (negatively charged) monomers forming a ternary complexe with a viologen-appended styrenic monomer. The same authors have also carried out similar studies with a viologen-substituted renewable cellulosic-based polymer leading to stimuli responsive self-assembled hydrogels with ultra-high water content (up to 99.7\%) (Figure 13). ${ }^{90}$

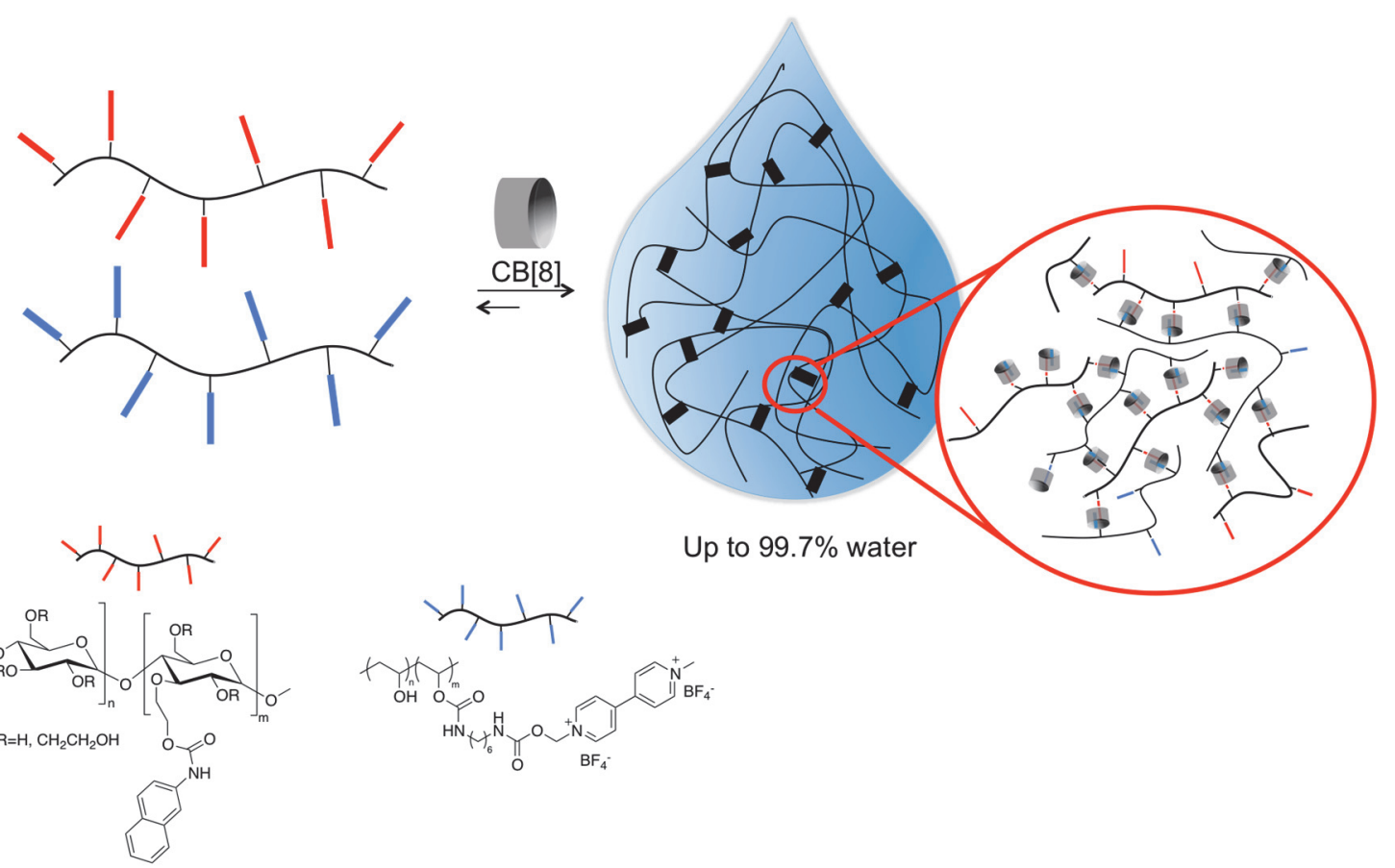

Figure 13 : Schematic representation of the 1:1:1 (CB[8]/viologen/naphtoxy) supramolecular ternary complexes yielding ultrahigh water content hydrogels. ${ }^{90}$

With the aim of developing efficient protein-based therapies, bovine serum albumin and lysozyme have been incorporated in suchCB8/viologen-containing ultra-high water content 
hydrogels. ${ }^{91}$ Contrary to the usual behavior encountered with regard to formulations at high concentrations in polymeric substituents, no strong burst release was observed with these high water content gels. Very recently, the same group managed to shape the threecomponents hydrogel as mono-disperse dehydrated beads using droplet-based microfluidics. In the presence of suitable amounts of $\mathrm{CB}[8]$, the beads, charged with fluorescein-tagged dextran during the droplet formation step, act as a model cargo retaining the fluorophore during re-hydration and releasing it rapidly upon addition of a competitive guest (1adamantylamine)..$^{92}$

Polymerization has also been achieved at the liquid/liquid interface upon formation of ternary complexes involving the viologen-based and diazobenzenepolytopic guests depicted in Figure 14 , and CB8. ${ }^{93}$ This supramolecular hyper-branched polymer could be dissociated upon photoirradiation or addition of a competitive guest. This polymer formed at the surface of water droplets was also found to inhibit their coalescence.
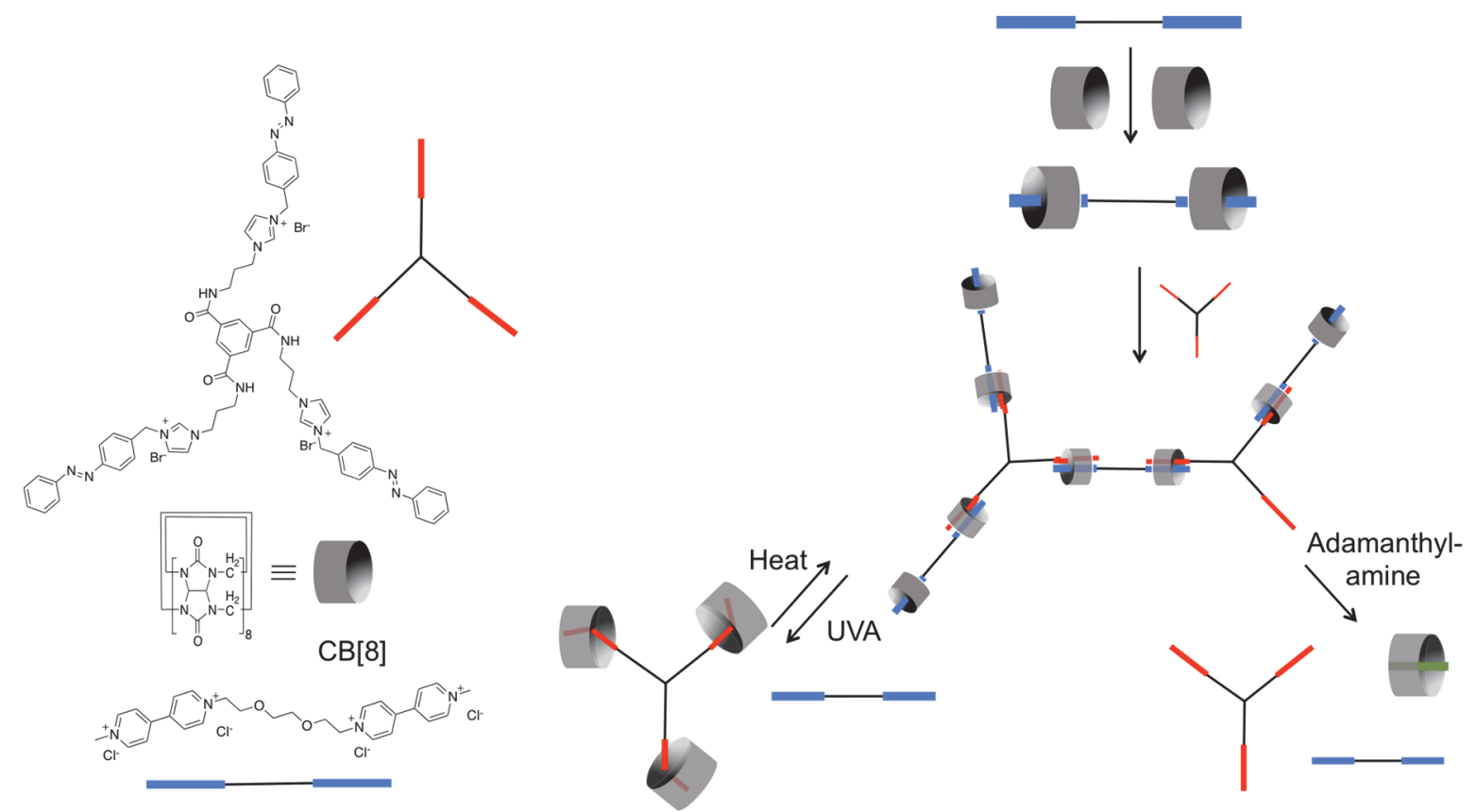

Figure 14 : Chemical structures and schematic representations of $C B[8]$, the ditopic and tritopic monomers (left). Overview of the proposed assembly process forming the supramolecular highly branched polymer (SHP) (left). This SHP can be disassembled in response to either (i) reversible photoisomerisation of the azobenzene, or (ii) introduction of a competitive guest. $^{93}$

Tan and coworkers have recently prepared hydrogels using a highly branched hydrophilic backbone with superior viscoelastic modulus and thermal stability highlighted as a next generation of aqueous polymeric supramolecular $\mathrm{CB}[8] /$ viologen assemblies. ${ }^{94}$ Their strategy is depicted in Figure 15: the usual three-components system (CB, donor, acceptor as depicted 
in Figure $12 \mathrm{~b}$ ) is replaced by a two-component system where $\mathrm{CB}[7$ or 8$]$ is threaded in polyrotaxanes structures.

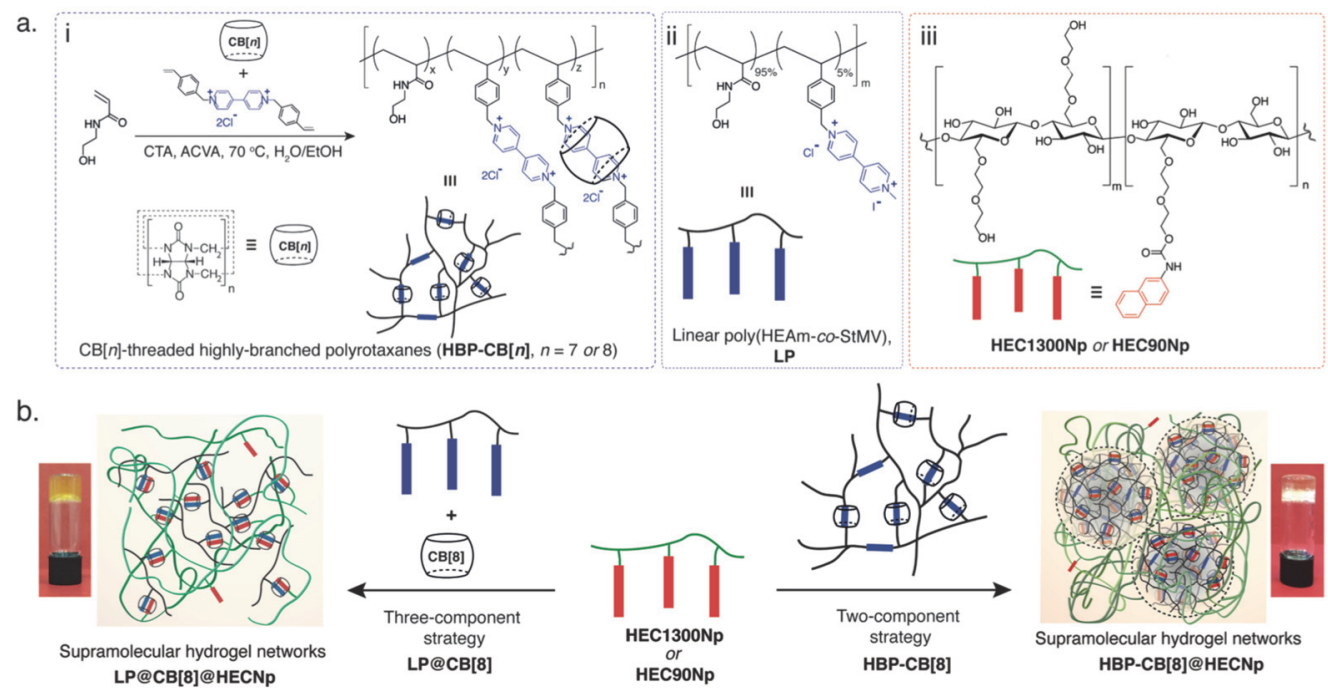

Figure $15:$ a) Schematic illustration of i) synthesis of the highly branched $C B[n]$-threaded polyrotaxane (HBP-CB[n]) via a semibatch RAFT polymerization in the presence of $C B[n]$, ii) chemical structures of its linear analog (LP), and iii) naphthylfunctionalized hydroxyethyl cellulose (HECNp). b) Formation of hydrogel networks through a two-component strategy from HBP-CB[8] polyrotaxane (HBP-CB[8]@HECNp) or a three-component strategy from its linear analog (LP@CB[8]@HECNp). Inset: inverted vial tests for the hydrogel networksfrom. ${ }^{94}$

Strictly speaking, the last two examples discussed below are not based on viologen units but rather on very similar, singly quaternized, structures. At basic $\mathrm{pHs}$, poly(N-(4-vinylbenzyl)-4,4'bipyridinium dichloride-co-acrylamide forms hydrogels in the presence of $\mathrm{CB}[8]$ following the association mode shown in Figure 12a, whereas acidic conditions induce a collapse ofthe 3Dnetwork structure. ${ }^{95}$ This investigation revealed that the 3D network hydrogel results from the formation of 1:2 CB[8]/viologen binary complexes between a poly( $\mathrm{N}$-(4-vinylbenzyl)-4,4'bipyridinium dichloride-co-acrylamide) and $\mathrm{CB}[8]$. The authors also demonstrate that the pore sizes within the xerogels decrease and the gel-sol transition temperature of hydrogels increases as the molar ratio of $\mathrm{CB}[8]$ to viologen units of copolymer increases.

The tetradentate guest TPE (Figure 16) is a tetraphenylethylene compound decorated with four mono-charged viologens. In presence of $\mathrm{CB}[8]$, this monomer was shown to afford binary complexes arranged into 2D-planar networks. These highly conjugated layers can stack on each other to form hydrogels. Those structures have been used to trap an aromatic anionic dye, namely the8-hydroxypyrene-1,3,6-trisulfonic acid (HPTS). ${ }^{96}$ 


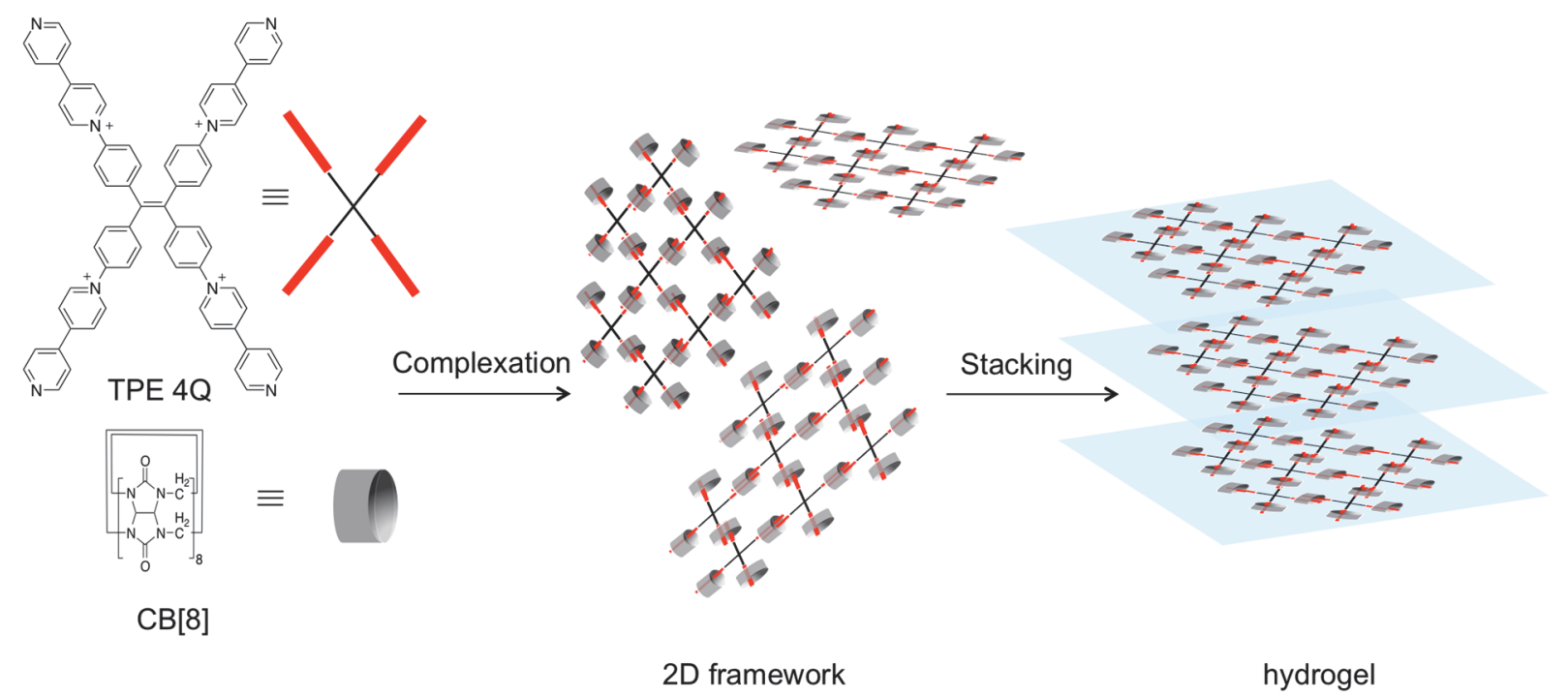

Figure 16. Hydrogel formation based on supramolecularassembly as 2D layers of a tetratopic guest and CB[8] followed by further inter layer stacking. ${ }^{96}$

\section{c. Films, superlattices and nanoparticles}

Self-assembled 1D chains, 2D sheets and 3D superlattices may be produced using viologenbased charge-transferpairs included in $\mathrm{CB}[\mathrm{n}]$, in a variety of ways, to achieve unprecedented complex sizes, structure-controlled arrays, and films. As a preliminary comment, it should be mentioned that a comprehensive review on nanoparticle arrays, held together by cavitands and host-guest interaction was provided recently by Li and Qi. ${ }^{97}$ Another one, concerning applications in medicine and healthcare, was published a few years ago by Zheng and his group. ${ }^{98}$

Layer-by-layer assembly (LBL) is a very useful technique to prepare thin films involving ion pairs. The substrate is initially dipped in the cation or anion solution and then in a second solution containing the complementary charged component (Figure $17 \mathrm{a}$ ). This procedure has proved quite efficient to produce very thin and regular alternated charged lamellar materials. The introduction of $\mathrm{CB}[\mathrm{n}]$ sallows the preparation of $\mathrm{LBL}$ films using solely cationic or anionic polymers. This principle was pioneeredby Ji and his group in 2013 using viologen or indolesubstituted poly(ethylenimine). ${ }^{99}$ The viologen groups ofthe first polymer were included in $\mathrm{CB}[8]$ and this first component was deposited over the substrates. Dipping the latter sample in a solution of the second polymer, containing indole groups, led to the formation of $\mathrm{CB}[8]$ stabilized charge-transfer complexes between the viologen and indole groups, holding the cationic chains in the assembly in the form of PEI-MV@CB[8]/PEI-ID (Figure 17 b). The growth 
of the film was followed by UV-vis absorption spectroscopy, ellipsometry and quartz microbalance over 12 bilayers, which proved stable over a wide $\mathrm{pH}$ range $(4 \leq \mathrm{pH} \leq 9)$. This work represents a very ingenious use of $L B L$ technique to produce multilayer films from either with cationic or anionic components.

a)

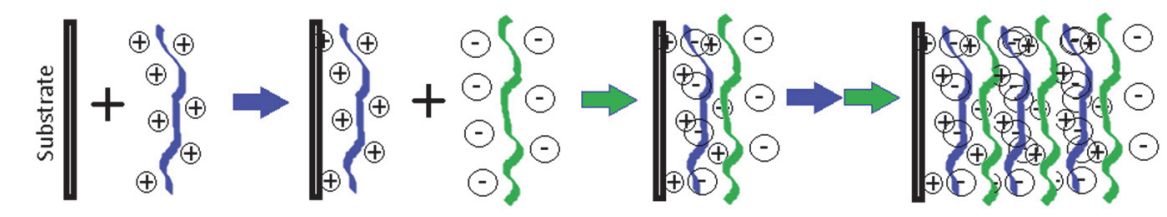

b)

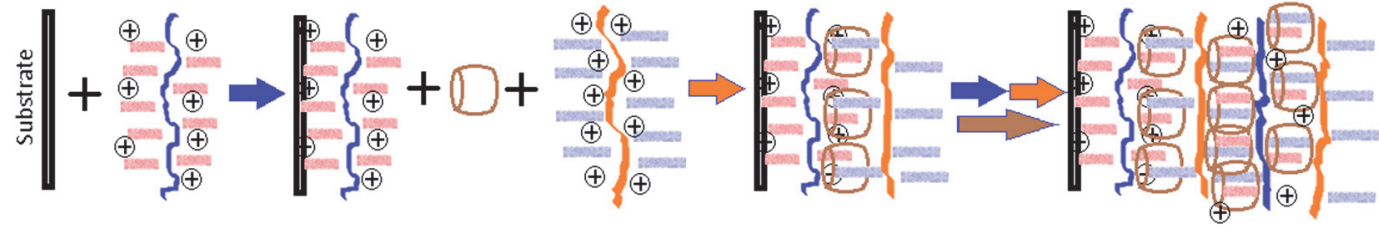

Figure 17 : Schematicrepresentation of the LBL deposition technique for a): classical ion-pair formation, and b): Host-stabilized charge-transfer pair (HSCT) LBL. ${ }^{99}$

It is well known that $\mathrm{CB}[\mathrm{n}] \mathrm{s}$ may act as growth regulators during nanoparticle synthesis. ${ }^{25,26}$ They usually bind by adsorption onto the particles surface and prevent the indefinite growth of metals and oxides for example. Trabolsi and his group have used this property to prepare arrays of CB[7] surface-modified magnetic iron oxide nanoparticles using 1,1'-diphenyl-4,4'bipyridinium(DPV) as a linker between adjacent nanoparticles forming dual host (2:1) ternary caviplexes (Figure 18). The same principle may be used with colloidal polymers based on poly(styrene). The hybrid assemblies may also be dissociated by reduction of the DPV moieties. ${ }^{100,101}$

Using the same approach, a series of micrometer scaled polymers containing particle clusters and arrays has been obtained by Abell and coworkers upon combining viologen- and naphthalene- modified particles in the presence of $\mathrm{CB}[8] .{ }^{102}$

Gold nanorods (AUNRs) maybe aligned as wires, using $\{100\}$ end-functionalized nanorods bearing pendant viologen groups. A dinaphthoxy (NAox) telechelic linker was used to form charge-transfer stabilized caviplexes with $\mathrm{CB}[8], \mathrm{MV}$ and NAox. The resulting head to tail aligned nanorod-based self-assembled oligomeric structures are clearly visible in TEM images. Such structures could not be observed with $\mathrm{CB}[7]$, due to its narrow size precluding insertion of two guests, nor in the presence of adamantine-amine, used as a competitive guest. ${ }^{103}$ Zhang and coll. have shown that $\mathrm{TiO}_{2}$ nanoparticles covalently functionalized with methylviologene substituents, can self-assemble in the presence of $\mathrm{CB}[8]$. The latter process is 
triggered by the one-electron (chemical or photochemical) reduction of the viologen units yielding cation radicals getting stabilized in CB[8] as inter-particular $\pi$-dimers (Figure 19). This process has been shown to be fully reversible and to modulate the nanoparticles catalytic activity. ${ }^{104}$

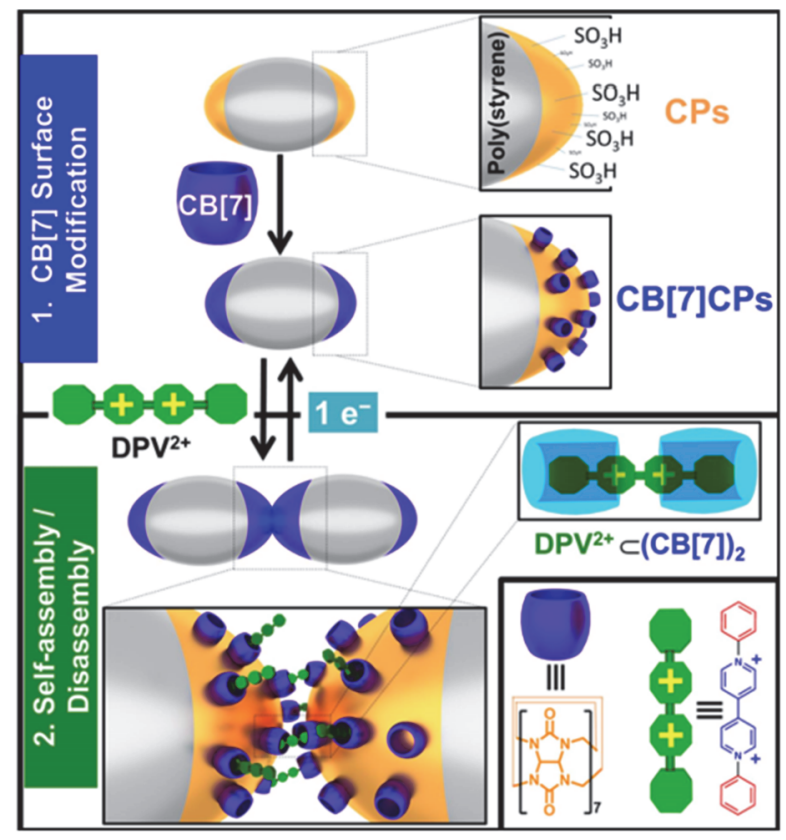

Figure 18:Self aggregation of polymeric colloidal particles using 2 hosts ternary caviplex and diphenylviologen (DPV). ${ }^{100,101}$

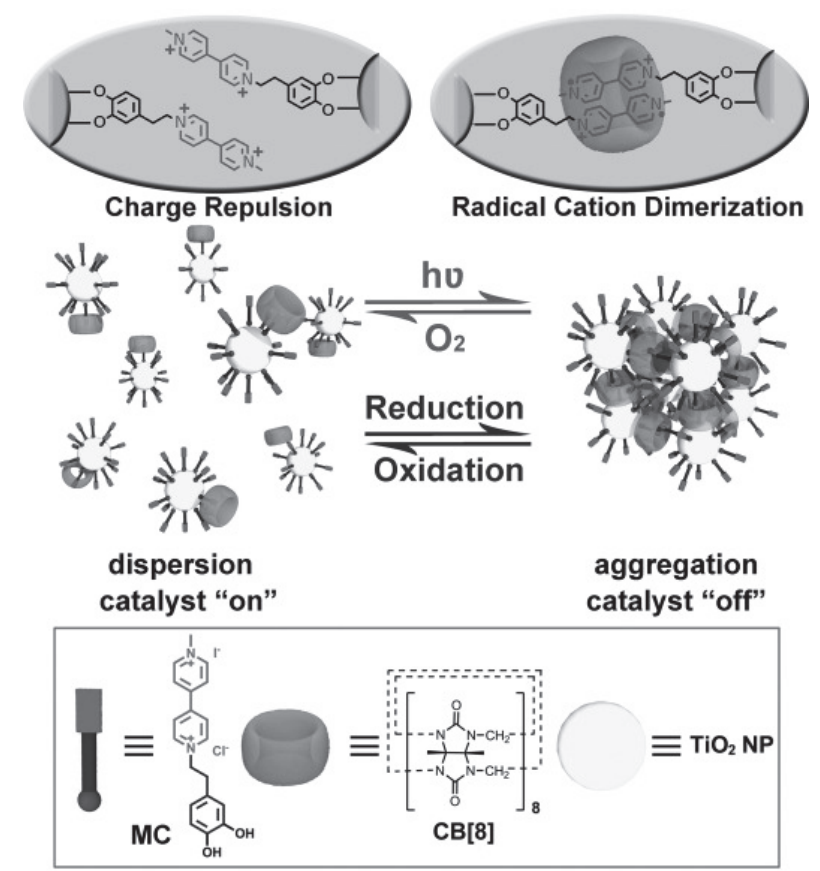

Figure 19: Reversible self-assembly of $\mathrm{TiO}_{2}$ nanoparticles modified with methyl viologens and cucurbit[8] uril. Aggregation may be triggered by light, or chemical reduction to form radical cations. Reoxidation of the later causes disassembly. ${ }^{104}$ 
A similar principle was used with metal-organic polyhedra (MOP) to deliver doxorubicin to cancer cells. A palladium MOP was prepared from $\mathrm{Pd}\left(\mathrm{NO}_{3}\right)_{2}$ and a methyl-viologen modified bipyridine ligand, which led to almost spherical MOPs with external MV pending groups. A doxorubicin pro-drug was then attached to the MOPs using naphtol residues and $\mathrm{CB}[8]$, forming charge-transfer pairs in hetero-guest caviplexes. The drug could be released by cleavage of an acid-sensitive acylhydrazone linkage in cellular medium. ${ }^{105}$

Supramolecular nanoparticles (SNP) have also been prepared from dendrimers such as poly(amidoamine) (PAMAM) modified with 8 terminal naphthol groups. Hetero-ternary caviplexes are formed in the presence of $\mathrm{CB}[8]$ and methyl viologen-poly(ethylene imine) (MVPEI). Additional layers can also be added using the affinity of the remaining uncoupled viologen moieties for naphthol-poly(ethylene glycol) (Np-PEG), or for any other naphthol derivative, as demonstrated by Stoffelen and Huskens. ${ }^{106-109}$ These procedures allow the obtention of monodisperse populations of self-assembled polymeric nanoparticles that could be used as carriers for example.A similar strategy has been produced patchy particles from colloidal carboxylated poly(styrene) clusters. ${ }^{110}$

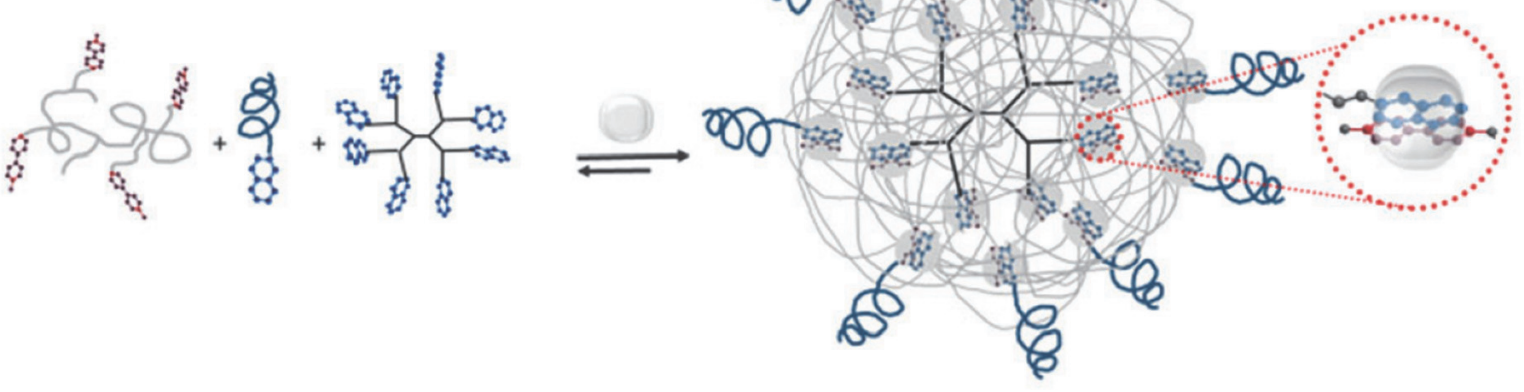

Figure 20: SNP formation starting from a first generation dendrimer (PAMAM) and other polymers. ${ }^{106}$

Shell-cleavable core-shell polymeric microspheres have been prepared by Scherman and his group using viologen-modified poly(acrylates) as scaffolds and $\mathrm{CB}[8]$ as supramolecular handcuffs to load different naphthol-appended polymers. The reversibility of ternary caviplex formation allows to hide or expose the inner polymer of the microsphere and to tune some key features as its citotoxicity for example. The shell can be dismantled using aminoadamantane, which has a higher affinity for $\mathrm{CB}[8]$ than any other guest. ${ }^{111}$ 
A similar approach was used by the same group to produce polymeric gold nanoparticles composites, using thiol modified viologens grafted onto the gold surface and naphtholfunctionalized polymers. ${ }^{112}$

Another interesting strategy relying on charge-transfer complexation to produce nanoparticle arrays involves the immobilization of $\mathrm{CB}[8]$-containing pseudo-rotaxanes over surfaces. Dual composition nano-patterned brushes have been prepared by Scherman and co-workers employing $\mathrm{CB}[8]$ - rotaxanes as supramolecular linking agents on gold surfaces to control the adhesion of trans-Azo functionalized silica colloids onto the surface in a hexagonal arrangement (Figure 21). ${ }^{113}$ This strategy may be employed to purify peptides containing aromatic donors such as phenylalanine or tryptophan, as demonstrated by Scherman and coworkers, ${ }^{114}$ or to prepare surface patterns with functionalized nanoparticles. ${ }^{113}$ Surface patterning with nanoparticles may be achieved similarly, using axial ternary inclusion compounds through functionalization of the surface with thiol-appended viologens and $\mathrm{CB}[8]$. The particles are then attached to the surface by use of electron-donating naphthol pendant groups. ${ }^{115}$

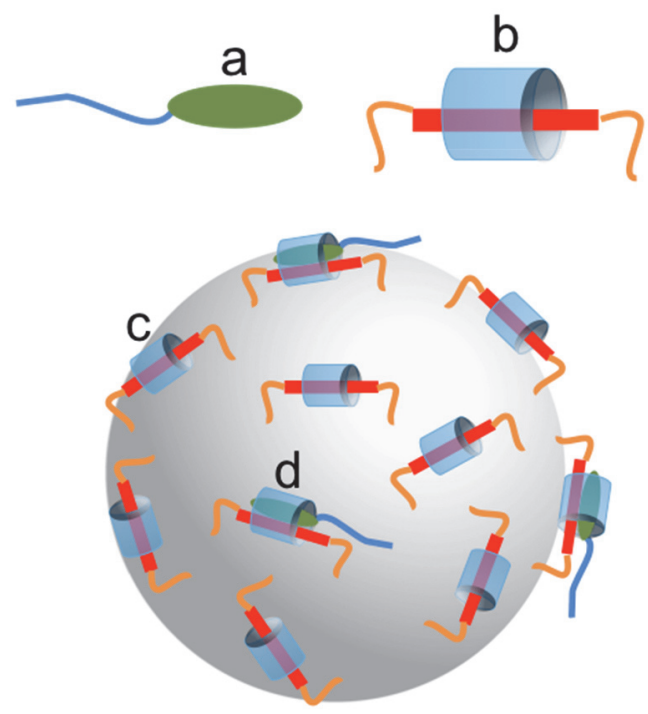

Figure 21: The catenane immobilization strategy over a spherical particle, a) an electron donor, b) a CB[8] pseudorotaxane containing a viologen core, c) the pseudorotaxane is immobilized, d) the pseudorotaxane accommodates the electron donor, forming a host-stabilized ternary charge-transfer complex. ${ }^{115}$

\section{Conclusion}

This review has highlighted state-of-the-art achievements in the field of supramolecular polymers built from viologens and cucurbit[n]urils. The abundant literature on this subject 
reveal that those two building blocks can be self-assembled in a number of ways to form a variety of inclusion compounds featuring different stoichiometries and dimentionalities. Due to size issues, only one viologen can be fitted inside the cavity of $\mathrm{CB}[7]$ to form a binary caviplex. This cucurbituril host can thus only be threaded on linear viologen-based oligomer/polymer strings or alternatively used in combination with a bis-viologen linker to promote the formation of polymeric structures. The ability of $\mathrm{CB}[8]$ host to form ternary homo or hetero-guest caviplexes has conversely proved far more suited to the development of 1D or $2 \mathrm{D}$ self-assembled supramolecular polymers. $\mathrm{CB}[8]$ can indeed either stabilize two viologen cation radicals as a pi-dimer or two $\pi$-conjugated moieties forming a donor-acceptor chargetransfer complex. These ternary caviplexes moreover provide key directional, dynamic and responsive features to the self-assembled polymers. Most $\mathrm{CB}[8]$-promoted assemblies can indeed be dismantled by equilibrium dynamics, in the presence of competitive guests such as adamantane or by simple reoxidation (with oxygen) of the viologen cation radicals. One approach towards viologene/CB[n]-based polymers involves "molecular handcuffs", wherein the macrocylic host stabilizes and thus restrains the freedom degrees of the guests. This strategy and many other ones have been devised and successfully implemented to develop a wide range of supramolecular polymers and materials including stimuli-responsive vesicles, gels, nanoparticle arrays and shell-cleavable particles used for instance as responsive carriers for drug delivery.

Much remains to be done in the field of supramolecular polymers with cucurbiturils and viologens. The only obstacles to the further development of such dynamic materials and to their applications might well be the limited solubility of $\mathrm{CB}[8]$ in aqueous media and the synthetic locks currently limitting the functionnalization of $C B[n]$.

\section{Acknowledgments}

The authors thank the joint AUCANI (Universidade de São Paulo)-UdL (Université de Lyon) Seed Funding and by the COFECUB program (COFECUB Uc Ph-C 168-17) as well as the Universidade de São Paulo and the Ecole Normale Supérieure de Lyon (ENSL) for financial, logistical and administrative supports. FAPESP (2016/12666-1) and CNPq (309570/2015-8) are also aknowledged. 


\section{References}

1 X.-Y. Hu, T. Xiao, C. Lin, F. Huang and L. Wang, Acc Chem Res 47:2041-2051 (2014).

$2 \quad$ P. W. K. Rothemund, Nature 440:297 (2006).

3 O. J. G. M. Goor, S. I. S. Hendrikse, P. Y. W. Dankers and E. W. Meijer, Chem Soc Rev 46:6621-6637 (2017).

$4 \quad$ S. Dong, B. Zheng, F. Wang and F. Huang, Acc Chem Res 47:1982-1994 (2014).

$5 \quad$ X.-Q. Wang, W. Wang, Y.-X. Wang and H.-B. Yang, Chem Lett 44:1040-1046 (2015).

6 L. Yang, X. Tan, Z. Wang and X. Zhang, Chem Rev 115:7196-7239 (2015).

7 X. Yang, H. Yu, L. Wang, R. Tong, M. Akram, Y. Chen and X. Zhai, Soft Matter 11:1242$1252(2015)$.

8 G. P. Moss, P. A. S. Smith and D. Tavernier, Pure Appl Chem 67:1307 (1995).

9 L. Striepe and T. Baumgartner, Chem Eur J 23:16924-16940 (2017).

10 Y. Wang, M. Frasconi and J. F. Stoddart, ACS Cent Sci 3:927-935 (2017).

11 A. C. Fahrenbach, C. J. Bruns, H. Li , A. Trabolsi, A. Coskun and J. F. Stoddart, Acc Chem Res 47: 482-493 (2014).

12 A. C. Fahrenbach, Z. Zhu, D. Cao, W.-G. Liu, H. Li, S. K. Dey, S. Basu, A. Trabolsi, Y. Y. Botros, I. W. A. Goddard and J. F. Stoddart, J Am Chem Soc 134:16275-16288 (2012).

13 C. L. Bird and A. T. Kuhn, Chem Soc Rev 10:49-82 (1981).

14 P. M. S. Monk, D. R. Rosseinsky and R. J. Mortimer, Electrochromic Materials and Devices Based on Viologens, in Electrochromic Materials and Devices, ed by P. M. S. Monk, D. R. Rosseinsky and R. J. Mortimer (2015).

15 D.-W. Zhang, J. Tian, L. Chen, L. Zhang and Z.-T. Li, Chem Asian J 10:56-58 (2015).

16 C. Kahlfuss, E. Saint-Aman and C. Bucher, Redox-controlled intramolecular motions triggered by $\pi$-dimerization and $\pi$ merization processes, in Organic Redox Systems: Synthesis, Properties, and Applications, ed by T. Nishinaga. John Wiley and sons, NewYork, pp. 39-88 (2016).

17 J. Lagona, P. Mukhopadhyay, S. Chakrabarti and L. Isaacs, Angew Chem, Int Ed Engl 44:4844-4870 (2005).

18 G. J.-F. Demets, Quim Nova 30:1313-1322 (2007).

19 G. C. Bolfarini, M. P. Siqueira-Moura, G. J. F. Demets, P. C. Morais and A. C. Tedesco, J Photochem Photobiol B: Biol 115:1-4 (2012).

20 G. C. Bolfarini, M. P. Siqueira-Moura, G. J. F. Demets and A. C. Tedesco, Dyes Pigm 100:162-167 (2014).

21 K. R. K. K. Reddy, T. S. T. S. Cavallini, G. J. F. Demets and L. F. Silva Jr, New J Chem 38:2262-2264 (2014).

22 C. B. Tovani, J. F. V. de Souza, T. S. Cavallini, G. J. F. Demets, A. Ito, M. B. Barioni, W. M. Pazin and M. E. D. Zaniquelli, Colloid Surf, B 111:398-406 (2013).

23 F. A. Silva, F. Huguenin, S. M. de Lima and G. J. F. Demets, Inorg Chem Front 1:495-502 (2014).

24 L. F. Stucchi da Silva, G. J.-F. Demets, C. Taviot-Gueho, F. Leroux and J. B. Valim, Chem Mater 23:1350-1352 (2011).

25 E. M. S. dos Santos, L. S. Pereira and G. J. F. Demets, J Braz Chem Soc 22:1595-1600 (2011).

26 L. F. S. da Silva, F. Leroux, C. Taviot-Guého, J. B. Valim and G. J. F. Demets, Synth React Inorg Metal-Organic Nano-Metal Chem 43:1078-1082 (2013). 
S. M. de Lima, J. A. Gomez, V. P. Barros, G. d. S. Vertuan, M. d. D. Assis, C. F. O. Graeff and G. J. F. Demets, Polyhedron 29:3008-3013 (2010).

28 H. D. Correia and G. J. F. Demets, Electrochem Commun 11:1928-1931 (2009).

29 M. C. Tadini, M. A. Balbino, I. C. Eleoterio, L. S. de Oliveira, L. G. Dias, G. J. F. Demets and M. F. de Oliveira, Electrochim Acta 121:188-193 (2014). J. Liu, Y. Lan, Z. Yu, C. S. Y. Tan, R. M. Parker, C. Abell and O. A. Scherman, Acc Chem Res 50:208-217 (2017).

31 K. I. Assaf and W. M. Nau, Chem Soc Rev 44:394-418 (2015).

32 A. Koc and D. Tuncel, Isr J Chem 58:334-342 (2017).

33 C. Hou, Z. Huang, Y. Fang and J. Liu, Org Biomol Chem 15:4272-4281 (2017).

34 E. Masson, M. Raeisi and K. Kotturi, Isr J Chem 58:413-434 (2018).

35 Z. Huang and X. Zhang, Cucurbit[ $\mathrm{n}$ ]uril-Mediated Multiple Interactions, in Multivalency: Concepts, Research \& Applications, ed by J. Huskens, L. J. Prins, R. Haag and B. J. Ravoo, pp. 143-152 (2018).

36 Y. Liu, H. Yang, Z. Wang and X. Zhang, Chem Asian J 8:1626-1632 (2013).

37 L. Cao, M. Šekutor, Y. Zavalij Peter, K. Mlinarić - Majerski, R. Glaser and L. Isaacs, Angew Chem, Int Ed Engl 53:988-993 (2014).

38 W. Ong, M. Gomez-Kaifer and A. E. Kaifer, Org Lett 4:1791-1794 (2002).

39 W. S. Jeon, H. J. Kim, C. Lee and K. Kim, Chem Commun 1828-1829 (2002).

40 C. Kahlfuss, S. Denis-Quanquin, N. Calin, E. Dumont, M. Garavelli, G. Royal, S. Cobo, E. Saint-Aman and C. Bucher, J Am Chem Soc 138:15234-15242 (2016).

41 C. Kahlfuss, E. Métay, M.-C. Duclos, M. Lemaire, A. Milet, E. Saint-Aman and C. Bucher, Chem Eur J 21:2090 - 2106 (2014).

42 C. Kahlfuss, E. Métay, M.-C. Duclos, M. Lemaire, M. Oltean, A. Milet, E. Saint-Aman and C. Bucher, C R Chimie 17:505-511 (2014).

43 C. Kahlfuss, A. Milet, J. A. Wytko, J. Weiss, E. Saint-Aman and C. Bucher, Org Lett 17:4058-4061 (2015).

44 H. J. Kim, J. Heo, W. S. Jeon, E. Lee, J. Kim, S. Sakamoto, K. Yamaguchi and K. Kim, Angew Chem Int Ed Engl 40:1526-1529 (2001).

45 M. Xue, Y. Yang, X. Chi, X. Yan and F. Huang, Chem Rev 115:7398-7501 (2015).

46 Z.-J. Zhang, H.-Y. Zhang, L. Chen and Y. Liu, J Org Chem 76:8270-8276 (2011).

47 J. Kim, Y. Ahn, M. Park Kyeng, D. W. Lee and K. Kim, Chem Eur J 16:12168-12173 (2010).

48 W. Lee Jae, H. Ko Young, S. H. Park, K. Yamaguchi and K. Kim, Angew Chem, Int Ed Engl 40:746-749 (2001).

49 H. Yang, J. Hao and Y. Tan, J Polym Sci, Part A: Polym Chem 49:2138-2146 (2011).

50 F. Sakai, Z.-W. Ji, J.-H. Liu, G.-S. Chen and M. Jiang, Chin Chem Lett 24:568-572 (2013).

51 U. Rauwald and A. Scherman Oren Angew Chem, Int Ed Engl 47:3950-3953 (2008).

52 F. Biedermann, U. Rauwald, J. M. Zayed and O. A. Scherman, Chem Sci 2:279-286 (2011).

53 S. Deroo, U. Rauwald, C. V. Robinson and O. A. Scherman, Chem Commun 644-646 (2009).

54 J. M. Zayed, F. Biedermann, U. Rauwald and O. A. Scherman, Polym Chem 1:1434-1436 (2010).

55 L. Yang, Y. Bai, X. Tan, Z. Wang and X. Zhang, ACS Macro Lett 4:611-615 (2015).

56 Z.-J. Yin, Z.-Q. Wu, F. Lin, Q.-Y. Qi, X.-N. Xu and X. Zhao, Chin Chem Lett 28:1167-1171 (2017).

57 L. Isaacs, Acc Chem Res 47:2052-2062 (2014). 
58 A. Iordache, R. Kanappan, E. Métay, M.-C. Duclos, S. Pellet-Rostaing, M. Lemaire, A. Milet, E. Saint-Aman and C. Bucher, Org Biomol Chem 11:4383-4389 (2013).

59 A. lordache, P. Melfi, C. Bucher, M. Buda, J.-C. Moutet and J. L. Sessler, Org Lett 10:425428 (2008).

60 A. lordache, M. Oltean, A. Milet, F. Thomas, E. Saint-Aman and C. Bucher, J Am Chem Soc 134:2653-2671 (2012).

61 A. Iordache, M. Retegan, F. Thomas, G. Royal, E. Saint-Aman and C. Bucher, Chem Eur J 18:7648 - 7653 (2012).

62 R. Kannappan, C. Bucher, E. Saint-Aman, G. Royal, J.-C. Moutet, A. Milet, M. Oltean, E. Métay, S. Pellet-Rostaing, M. Lemaire and C. Chaix, New J Chem 34:1373-1386 (2010).

63 J. M. Spruell, Pure Appl Chem 82:2281-2294 (2010).

64 D. W. Zhang, J. Tian, L. Chen, L. Zhang and Z. T. Li, Chem Eur J 10:56-68 (2015).

65 Y. H. Ko, E. Kim, I. Hwang and K. Kim, Chem Commun 1305-1315 (2007).

66 T.-G. Zhan, T.-Y. Zhou, F. Lin, L. Zhang, C. Zhou, Q.-Y. Qi, Z.-T. Li and X. Zhao, Org Chem Front 3:1635-1645 (2016).

67 Zhang, L., T.-Y. Zhou, J. Tian, H. Wang, D.-W. Zhang, X. Zhao, Y. Liu and Z.-T. Li, Polym Chem 5:4715-4721 (2014).

68 X.-L. Ni, S. Chen, Y. Yang and Z. Tao, J Am Chem Soc 138:6177-6183 (2016).

69 K. Madasamy, S. Vellaiahmaruthiah, D. Velayutham and K. Murugavel, Scientific Reports 8:1354 (2018).

70 H. Qian, D.-S. Guo and Y. Liu, Chem Eur J 18:5087-5095 (2012).

71 J. del Barrio, P. N. Horton, D. Lairez, G. O. Lloyd, C. Toprakcioglu and O. A. Scherman, J Am Chem Soc 135:11760-11763 (2013).

72 T.-T. Cao, X.-Y. Yao, J. Zhang, Q.-C. Wang and X. Ma, Chin Chem Lett 26:867-871 (2015).

73 L. Zou, Z. Yuan, D. Chang and X. Ma, Dyes and Pigments 143:211-216 (2017).

74 J. Geng, F. Biedermann, J. M. Zayed, F. Tian and O. A. Scherman, Macromolecules 44:4276-4281 (2011).

75 E. Cavatorta, M. L. Verheijden, W. van Roosmalen, J. Voskuhl, J. Huskens and P. Jonkheijm, Chem Commun 52:7146-7149 (2016).

76 D. Jiao, J. Geng, X. J. Loh, D. Das, T. C. Lee and O. A. Scherman, Angew Chem Int Ed Engl 51:9633-9637 (2012).

77 L. Yang, H. Yang, F. Li and X. Zhang, Langmuir 29:12375-12379 (2013).

78 X. J. Loh, J. del Barrio, T.-C. Lee and O. A. Scherman, Chem Commun 50:3033-3035 (2014).

79 Z. Yu, Y. Zheng, R. M. Parker, Y. Lan, Y. Wu, R. J. Coulston, J. Zhang, O. A. Scherman and C. Abell, ACS App Mater Interfaces 8:8811-8820 (2016).

80 D. Wu, Y. Li, J. Yang, J. Shen, J. Zhou, Q. Hu, G. Yu, G. Tang and X. Chen, ACS App Mater Interfaces 9:44392-44401 (2017).

81 C. Hu, N. Ma, F. Li, Y. Fang, Y. Liu, L. Zhao, S. Qiao, X. Li, X. Jiang, T. Li, F. Shen, Y. Huang, Q. Luo and J. Liu, Appl Mater Interfaces 10:4603-4613 (2018).

82 J. H. Mondal, S. Ahmed, T. Ghosh and D. Das, Soft Matter 11:4912-4920 (2015).

83 E. M. White, J. Yatvin, J. B. Grubbs, J. A. Bilbrey and J. Locklin, J Polym Sci, Polym Phys 51:1084-1099 (2013).

84 J. W. Steed, Chem Commun 47:1379-1383 (2011).

85 A. S. Hoffman, Adv Drug Deliv Rev 64:18-23 (2012).

86 M. J. Rowland, M. Atgie, D. Hoogland and O. A. Scherman, Biomacromolecules 16:2436-2443 (2015). 
87 Y. Lin, L. Li and G. Li, Carbohydrate Polym 92:429-434 (2013).

88 H. Chen, S. Hou, H. Ma, X. Li and Y. Tan, Scientific Reports 6:20722 (2016).

89 E. A. Appel, F. Biedermann, U. Rauwald, S. T. Jones, J. M. Zayed and O. A. Scherman, J Am Chem Soc 132:14251-14260 (2010).

90 E. A. Appel, X. J. Loh, S. T. Jones, F. Biedermann, C. A. Dreiss and O. A. Scherman, J Am Chem Soc 134:11767-11773 (2012).

91 E. A. Appel, X. J. Loh, S. T. Jones, C. A. Dreiss and O. A. Scherman, Biomaterials 33:46464652 (2012).

92 X. Xu, E. A. Appel, X. Liu, R. M. Parker, O. A. Scherman and C. Abell, Biomacromolecules 16:2743-2749 (2015).

93 A. S. Groombridge, A. Palma, R. M. Parker, C. Abell and O. A. Scherman, Chem Sci 8:1350-1355 (2017).

94 C. S. Y. Tan, J. Liu, A. S. Groombridge, S. J. Barrow, C. A. Dreiss and O. A. Scherman, Adv Func Mater 28:1702994-1703000 (2018).

95 H. Yang, H. Chen and Y. Tan, RSC Adv 3:3031-3037 (2013).

96 X.-M. Chen, Y.-M. Zhang and Y. Liu, Supramol Chem 28:817-824 (2016).

97 D. Li and L. Qi, Curr Opin Colloid Interface 35:59-67 (2018).

98 Z. Wu, N. Song, R. Menz, B. Pingali, Y.-W. Yang and Y. Zheng, Nanomedicine 10:14931514 (2015).

99 D.-d. Li, K.-f. Ren, H. Chang, H.-b. Wang, J.-I. Wang, C.-j. Chen and J. Ji, Langmuir 29:14101-14107 (2013).

100 F. Benyettou, K. Nchimi - Nono, M. Jouiad, Y. Lalatonne, I. Milosevic, L. Motte, J. C. Olsen, N. i. Saleh and A. Trabolsi, Chem Eur J 21:4607-4613 (2015).

101 F. Benyettou, X. Zheng, E. Elacqua, Y. Wang, P. Dalvand, Z. Asfari, J.-C. Olsen, D. S. Han, N. i. Saleh, M. Elhabiri, M. Weck and A. Trabolsi, Langmuir 32:7144-7150 (2016).

102 X. Xu, F. Tian, X. Liu, R. M. Parker, Y. Lan, Y. Wu, Z. Yu, O. A. Scherman and C. Abell, Chem Eur J 21:15516-15519 (2015).

103 S. T. Jones, J. M. Zayed and O. A. Scherman, Nanoscale 5:5299-5302 (2013).

104 Q. Zhang, D. H. Qu, Q. C. Wang and H. Tian, Angew Chem Int Ed Eng/ 54:15789-15793 (2015).

105 S. K. Samanta, D. Moncelet, V. Briken and L. Isaacs, J Am Chem Soc 138:14488-14496 (2016).

106 C. Stoffelen and J. Huskens, Chem Commun 49:6740-6742 (2013).

107 C. Stoffelen and J. Huskens, Small 12:96-119 (2016).

108 C. Stoffelen, E. Staltari-Ferraro and J. Huskens, J Mater Chem B 3:6945-6952 (2015).

109 C. Stoffelen, J. Voskuhl, P. Jonkheijm and J. Huskens, Angew Chem Int Ed Eng/ 53:34003404 (2014).

110 E. Elacqua, X. Zheng and M. Weck, ACS Macro Lett 6:1060-1065 (2017).

111 Y. Lan, X. J. Loh, J. Geng, Z. Walsh and O. A. Scherman, Chem Commun 48:8757-8759 (2012).

112 R. J. Coulston, S. T. Jones, T.-C. Lee, E. A. Appel and O. A. Scherman, Chem Commun 47:164-166 (2011).

113 C. Hu, Y. Lan, K. R. West and O. A. Scherman, Adv Mater 27:7957-7962 (2015).

114 X. Ren, Y. Wu, D. E. Clarke, J. Liu, G. Wu and O. A. Scherman, Chem Asian J 11:23822386 (2016).

115 F. Tian, N. Cheng, N. Nouvel, J. Geng and O. A. Scherman, Langmuir 26:5323-5328 (2010). 
